\title{
Long-Range $\pi$-Conjugation in Phenothiazine-containing Donor-Acceptor Dyes for Application in Dye-Sensitized Solar Cells
}

\author{
Mini P. Antony, ${ }^{[a, b]}$ Thomas Moehl, ${ }^{[a]}$ Mateusz Wielopolski, ${ }^{[c]}$ Jacques-E. Moser, ${ }^{[c]}$ \\ Shantikumar Nair, ${ }^{[b]}$ Yong-Jae Yu, ${ }^{[d]}$ Jong-Hyung Kim, ${ }^{[d]}$ Kwang-Yol Kay, ${ }^{*[d, e]}$ Young- \\ Sam Jung, ${ }^{[f]}$ Kyung Byung Yoon, ${ }^{[f]}$ Carole Grätzel, ${ }^{[a]}$ Shaik M. Zakeeruddin, ${ }^{*[a]}$ and \\ Michael Grätzel*[a]
}

Four organic donor- $\pi$-bridge-acceptor dyes containing pheno-
thiazine as a spacer and cyanoacrylic acid as an acceptor were
synthesized and tested as sensitizers in dye-sensitized solar
cells (DSCs). The influence of iodide- and cobalt-based redox
electrolytes on the photovoltaic device performance was inves-
tigated. In these new dyes, systematic $\pi$-conjugation was ex-
tended by inserting one or two phenothiazine moieties and in-
vestigated within the context of the resulting photoinduced
charge-transfer properties. A detailed investigation, including
transient absorption spectroscopy and quantum chemical methods, provided important information on the role of extended $\pi$-conjugation on the photophysical properties and photovoltaic device performance. Overall, the results showed that the extension of $\pi$-conjugation by one phenothiazine unit resulted in the best device performance owing to reduced recombination rates, whereas extension by two phenothiazine units reduced dye adsorption on $\mathrm{TiO}_{2}$ probably owing to the increase in molecular size. The performance of the dyes in DSCs was found to be a complex interaction between dye structure and size.

\section{Introduction}

Dye sensitized solar cells (DSCs) have attracted considerable attention in recent years owing to low cost and high efficiency. ${ }^{[1]}$ The DSCs based on ruthenium sensitizers have reached overall power conversion efficiency (PCE) of over $11 \%$ under standard AM 1.5G illumination. Many efforts have been devoted to develop efficient metal-free sensitizers for practical use owing to their high molar absorption coefficient, ease of synthesis, scalability, and structural modifications. The PCE of donor- $\pi$ bridge-acceptor $(D-\pi-A)$ organic sensitizers has reached more than $12 \%$ making them attractive candidates for use as sensitizers for DSC. ${ }^{[2]}$ A zinc porphyrin donor-acceptor dye already reached $13 \%$ power conversion efficiency in conjunction with a cobalt-based redox electrolyte. ${ }^{[3]}$ In search of efficient D- $\pi-A$ organic sensitizers, several donor groups such as diphenylamine ${ }^{[4]}$ carbazole, ${ }^{[5]}$ triphenylamine ${ }^{[6]}$ indoline, ${ }^{[7]}$ coumarin, ${ }^{[8]}$ pyrrolidine ${ }^{[9]}$ and phenothiazine ${ }^{[10]}$ were used. However, little is reported on the use of phenothiazine as a $\pi$-bridge in $D-\pi-A$ sensitizers. ${ }^{[11]}$

Organic dyes containing oligo-phenothiazine were used as both the electron donor and as the $\pi$-conjugated spacer in sensitizers for DSC. It is additionally reported that long $\pi$ bridges can adversely affect photovoltaic device performance. ${ }^{[12]}$ In this study we combine these concepts to systematically varied the $\pi$-bridge length by introducing 0,1 , or 2 [a] Dr. M. P. Antony, Dr. T. Moehl, Dr. C. Grätzel, Dr. S. M. Zakeeruddin,

Prof. Dr. M. Grätzel

Laboratory for Photonics and Interfaces

Institute of Chemical Sciences and Engineering

Swiss Federal Institute of Technology

1015 Lausanne (Switzerland)

E-mail:shaik.zakeer@epfl.ch michael.graetzel@epfl.ch

[b] Dr. M. P. Antony, Prof. Dr. S. Nair

Amrita Centre for Nanosciences and Molecular Medicine Amrita Vishwa Vidyapeetham

Amrita lane, Edappally, Cochin-41 682041 (India)

[c] Dr. M. Wielopolski, Prof. Dr. J.-E. Moser

Photochemical Dynamics Group, Institute of Chemical Sciences and Engineering

Ecole Polytechnique Fédérale de Lausanne

1015 Lausanne (Switzerland) [d] Y.-J. Yu, J.-H. Kim, K.-Y. Kay

Solar Sys Co., Ltd., BI Center

[e] K.-Y. Kay

Department of Molecular Science and Technology

Ajou University

Suwon 443-749 (Korea)

E-mail:kykay@ajou.ac.kr

[f] Y.-S. Jung, K. B. Yoon

Korea Center for Artificial Photosynthesis

Department of Chemistry

Sogang University

Seoul 121-742 (Korea)

$\square$ Supporting Information for this article is available on the WWW under http://dx.doi.org/10.1002/cssc.201500931. 
phenothiazine units between the donor and acceptor. We compared the influence of this change on the respective photovoltaic device performances and photophysical properties. Phenothiazine groups were also introduced as electron donors along with the triphenylamine unit to increase the donor strength and decrease the aggregation. ${ }^{[13]}$ Compared with triarylamines, commonly used as electron donors, the phenothiazine molecule possesses some unique features. Phenothiazine is an electron rich molecule owing to the presence of electron rich nitrogen and sulphur in the central ring. Phenothiazine is a non-planar molecule with a slightly bent structure at the central ring. The non-planar structure of phenothiazine, and the presence of alkyl chain on the nitrogen atom, can reduce molecular aggregation, which would help to reduce charge recombination and obtain higher device performance. In this study four new organic $D-\pi-A$ dyes containing phenothiazine as a $\pi$-bridge and cyanoacrylic acid as an acceptor were designed, synthesized, and tested as sensitizers in DSCs. To clarify the relationship between the photovoltaic properties and the molecular structures, electrochemical studies and photoinduced electron transfer properties of these new molecules were also obtained.

\section{Results and Discussion}

\section{Synthesis}

The molecular structures of dye A-D are shown in Scheme 1. The preparation of the organic sensitizers A, B (S1), C (S2), and D (S3) was performed by following the steps as depicted in Scheme S1 in the Supporting Information. Every step of the reaction sequence proceeded smoothly and efficiently to give a good or moderate yield of the product (see the Supporting Information for the synthetic details). The model compound A was synthesized according to the literature method. ${ }^{[14]}$ The vinyl groups in compounds S5 and S7 were introduced through Wittig reactions of the corresponding aldehydes. ${ }^{[14]}$ The aldehydes S6, S8, and S10 were synthesized by the Heck reaction between the $-\mathrm{Br}$ group of $\mathrm{S} 4$ and $\mathrm{S} 9$ with the vinyl group of $\mathrm{S} 5$ and $\mathrm{S} 7$ using $\mathrm{Pd}(\mathrm{OAc})_{2}$ as catalyst. Knoevenagel condensation of compounds S6, S8, and S10 with cyanoacetic acid in the presence of piperidine produced the sensitizer $\mathbf{B}$ (S1), C (S2) and D (S3), respectively.
In general extending the $\pi$-conjugation of a sensitizer enhances the intermolecular interaction and consequently increases dye aggregation, which hinders the device performance. In our case, we designed the dye molecules in such a way that there is limited dye aggregation on the surface of the $\mathrm{TiO}_{2}$ photoanode owing to the non-planar structure of phenothiazine. As shown in Scheme 1, sensitizers A-D have different molecular structures, which are expected to influence the photovoltaic device performance by affecting the chargetransport properties of the dye. To clarify the relationship between the photovoltaic properties and the molecular structures, photoinduced electron-transfer properties of these molecules were studied and are discussed together with their electrochemical properties in the forth-coming section.

\section{Electronic absorption and energy levels}

Figures 1 and S1 show the steady-state absorption spectra of dyes A-D measured in $0.1 \mathrm{~mm}$ chlorobenzene solutions and adsorbed on $3 \mu \mathrm{m}$ mesoporous $\mathrm{TiO}_{2}$ films, respectively. In chlorobenzene, all dyes exhibit broad absorptions in the 280$600 \mathrm{~nm}$ region. The absorption band around $500 \mathrm{~nm}$ is attributed to intramolecular charge transfer (ICT) from the donor to the acceptor. The exact position of the red absorption edge depends on the chemical structure of the dyes and the conjugation length. In particular, it is possible to distinguish two different types of systematic $\pi$-conjugation extensions. Considering dyes $\mathbf{A}, \mathbf{C}$, and $\mathbf{D}$, the distance between the electron donat-

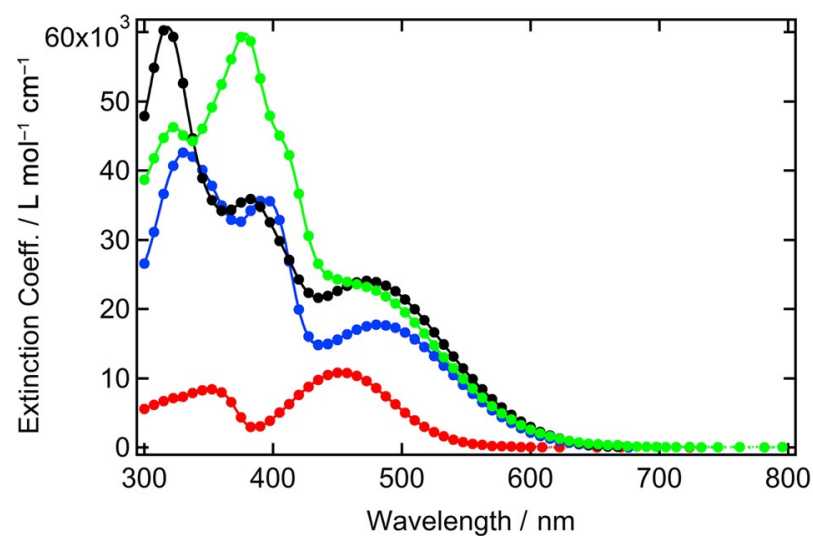

Figure 1. Absorption spectra of A-D in $0.1 \mathrm{~mm}$ chlorobenzene solutions. Color code: A: red; B: blue; C: green, D: black.

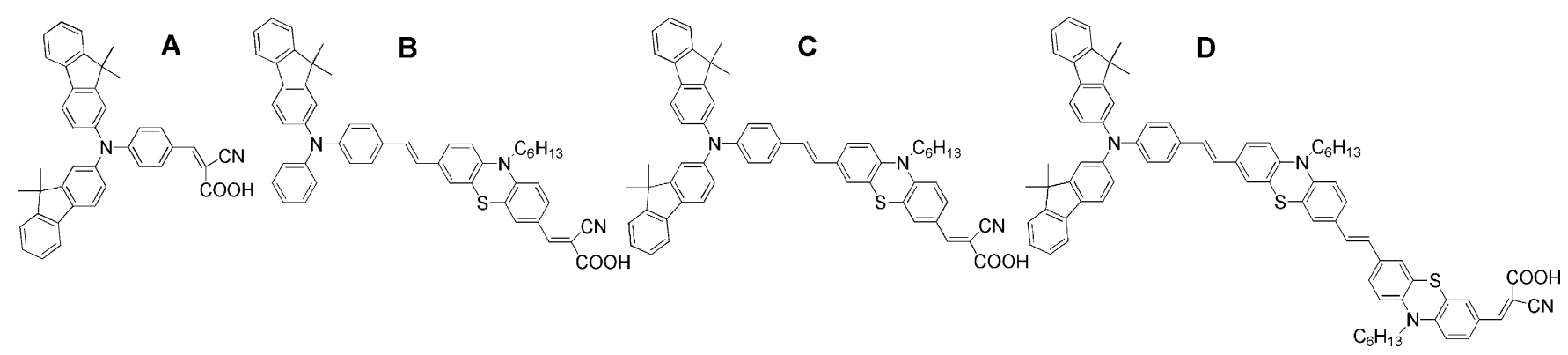

Scheme 1. Molecular structures of dyes A-D. 
ing difluorene-phenyl amine moiety (DPA) is systematically extended by inserting one or two vinylenehexylphenothiazine (VHP); this increase in the $\pi$-conjugation length between the donor and acceptor lowers the HOMO-LUMO gap. On the other hand, comparing $\mathbf{B}$ to $\mathbf{C}$, only the $\pi$-conjugation of the donor is extended by substitution of the phenyl ring in $\mathbf{B}$ by a fluorene moiety in $\mathbf{C}$. These two modes of $\pi$-extension- $\pi$-bridge or donor extension-have different effects on the absorption features of the molecules. Hence, in solution (Figure 1) the absorption bands are located at longer wavelengths and resemble the type of bands expected when extending the distance between the electron donating part and the acceptor/anchoring group, that is, the $\pi$-conjugation length. In A, the red maximum is located at approximately $450 \mathrm{~nm}$ with the red absorption edge at full width half maximum (FWHM) around $498 \mathrm{~nm}$. For $\mathbf{B}$ and $\mathbf{D}$, the maxima resulting from the extension of $\pi$-conjugation is shifted to 498 and $482 \mathrm{~nm}$, respectively. Thereby the red absorption edges at FWHM peaks shift gradually from $498 \mathrm{~nm}$ to $535 \mathrm{~nm}$ when going from $A$ to $B / C$ and then to $553 \mathrm{~nm}$ for $\mathbf{D}$, which reflects the gradual extension of the donor-acceptor distance. This trend becomes even more apparent when considering the spectra of the dyes as adsorbed on $\mathrm{TiO}_{2}$ films (Figure S1). Adsorption on $\mathrm{TiO}_{2}$ significantly changes the configurationally accessible degrees of freedom, which eliminates most of the fine structure of the spectra when compared to the absorption characteristics of these species in solution. Hence, on $\mathrm{TiO}_{2}$ the absorption appears as broad bands with clearly defined absorption edges. With the exception of dye $\mathbf{A}$, the absorption edges of the other dyes are shifted to the blue by approximately $20 \mathrm{~nm}$. This shift of the absorption to higher energies, that is, hypsochromic shift, after adsorption on $\mathrm{TiO}_{2}$ is ascribed to $\mathrm{H}$-aggregation and the deprotonation of the carboxylic acid and is more important in highly conjugated systems. ${ }^{[8 \mathrm{~g}]}$

The modification of the donor between $\mathbf{B}$ and $\mathbf{C}$, on the other hand, does not significantly affect the spectral positions of the absorption characteristics, but solely varies the relative intensities of the first band. The extinction coefficients of the broadest maximum increase with increasing $\pi$-conjugation length when comparing $\mathbf{A}$ to $\mathbf{B}, \mathbf{C}$, or $\mathbf{D}$ from a value of $1.1 \times$ $10^{4}$ to $1.8 \times 10^{4}, 2.3 \times 10^{4}$, and $2.4 \times 10^{4} \mathrm{M}^{-1} \mathrm{~cm}^{-}$, respectively. Conclusively, introducing the VMP units into the spacer between the donor and acceptor impacts the spectral shift of the dyes to a much greater extent than the $\pi$-conjugation of the donor.

Differential pulse voltammetry (DPV) was applied to measure the redox potentials of these dyes and the values are tabulated in Table 1 (for the DPV measurements see also Figure S1). The oxidation potential corresponds to the HOMO and estimations of the LUMO level were obtained by estimating the HOMO-LUMO energy gap $\left(E_{\mathrm{g}}\right)$ from the extrapolation of the slope of the low energy UV/Vis band to the $x$-axis (optical band gap, $\left.E_{\mathrm{g}}^{\mathrm{opt}}\right)$. Insertion of VHP units as a $\pi$-conjugating spacer leads to a new oxidation peak as visible in the DPV measurements for B-D. This shifts the HOMO level of these dyes to more negative potentials (on electrochemical scale), as can be seen in Table 1, and makes them easier to be oxidized. Therefore the absorption onset of the dyes B-D is shifted to lower energies (or longer wavelengths) and the HOMO-LUMO gap is reduced (Table 1). The HOMO levels of all the dyes are more positive than the energy level of the redox electrolyte (ca. $-4.76 \mathrm{eV}$ for the iodine electrolyte and $-5.00 \mathrm{eV}$ for the cobalt electrolyte), indicating that there is enough driving force for dye regeneration. All absorption features and electronic properties including absorption maxima, extinction coefficients, HOMO/LUMO gaps, and energies are summarized in Table 1.

\section{Molecular modelling}

In order to explore the geometrical and electronic properties of the four different dyes, the structures were optimized using density functional theory (DFT) with the B3LYP ${ }^{[16]}$ functional and the $6-31 \mathrm{G}^{*[17]}$ basis set as implemented into the Gaussian $09^{[18]}$ suite of programs. All optimized geometries are depicted in Figure 2. Owing to the rather limited basis set the linkers between the electron-donating and the acceptor/anchoring groups used in these computations are slightly more planar than would be expected in reality, as the phenothiazine does not possess an entirely planar configuration. However, the computational modelling clearly suggests that the molecules favor a configuration in which the overlap between the $p$-orbitals is maximized and efficient $\pi$-conjugation throughout the spacer is guaranteed. Hence, the linkers assume the role of molecular wires, effectively mediating electronic coupling between the donor and the acceptor sites of the molecules. ${ }^{[19]}$

The analysis of the electron density distribution of the frontier orbitals confirms the wire-like electronic communication between the donor and the acceptor parts of the molecule. As seen from the representation of the molecular orbitals in Figure 3, the HOMOs are localized on the electron donating part of the molecules. The HOMO coefficients reach far into 

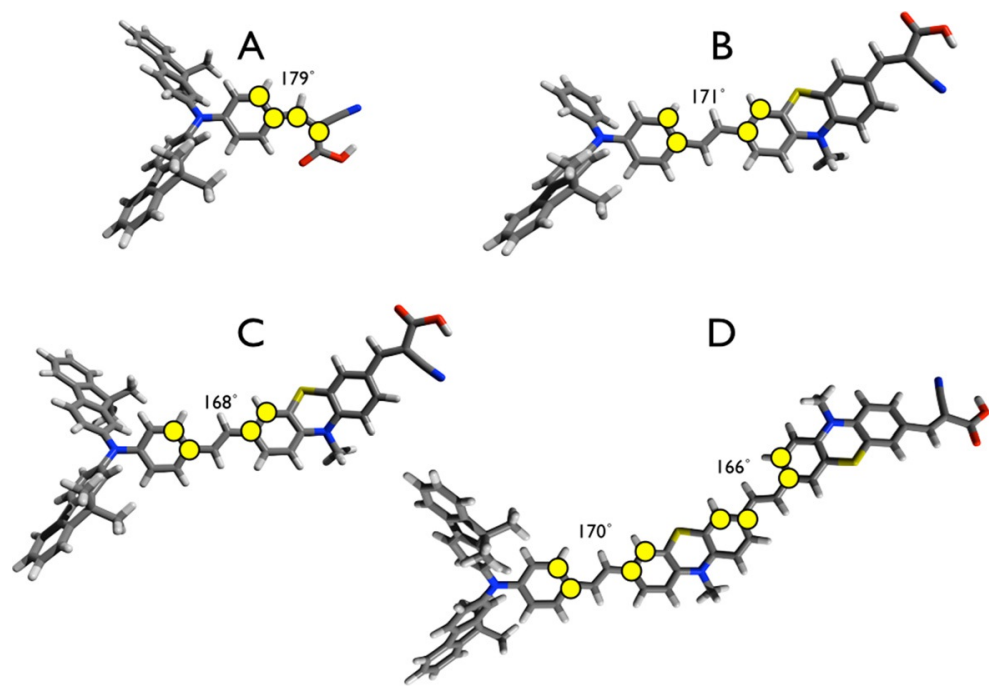

Figure 2. Optimized ground-state geometries including dihedral angles of the anchoring units of A-D computed using DFT B3LYP/6-31G* method.

the $\pi$-spacers resulting from the planar geometry. The LUMOs are localized on the electron accepting cyanoacrylic acid moiety. Since the distance between the donor and acceptor varies from 9 to $29 \AA$ for $A$ and $D$, respectively, significant differences between the dyes are found deriving from the HOMO-LUMO overlap. In $\mathbf{A}$, for instance, the HOMO and LUMO coefficients are nearly homogenously distributed over the structure and the HOMO-LUMO energy gap is $2.90 \mathrm{eV}$. Extending the conjugation by introducing one (B, C) or two (D) vinylene-methylphenothiazine (methyl derivative used as a representative structure to reduce computational cost) moieties significantly decouples the HOMO from the LUMO, which leads to a spatial separation of both orbitals. However, the vinylene linkers between the phenothiazines and the phenyl units of the donors allow for planar dihedral angles between those
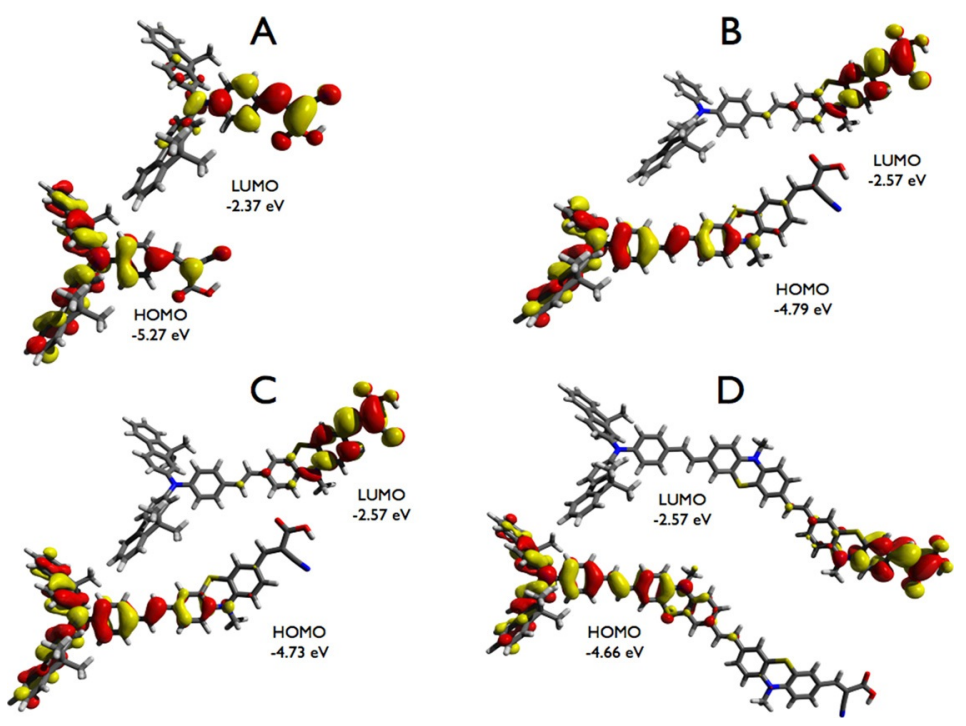

Figure 3. Frontier orbital representations with the corresponding energies of dyes A-D as computed using the DFT B3LYP/6-31G* method. units reaching nearly $180^{\circ}$. Such a nearly perfect planar configuration between the phenyls within the bridge enhances the $\pi$-overlap and appears to preserve the electronic communication between donor and acceptor sites throughout the entire system. The decreasing HOMO-LUMO energy gaps from $\mathbf{B}$ to $\mathbf{C}$ to D are a strong indication of the efficient electronic coupling through a high degree of $\pi$-conjugation. These findings are well in line with the ideas developed earlier concerning the steady-state absorption features. The strong electronic coupling is reflected in the broad absorption bands of the dyes (Figure 1). In vacuum, the HOMO-LUMO gaps of molecules B-D were calculated to be 2.22, 2.16, and $2.09 \mathrm{eV}$, respectively. Remarkably, the LUMO orbital energies remain constant for all the dyes with a value of $-2.57 \mathrm{eV}$. This proves that the structural variations of the linkers do not affect the electron accepting properties of the cyanoacrylic acid anchoring groups. Therefore, the electronic structure of the spacer between the donor and the acceptor sites permits increased distances between the two moieties without altering the electronic coupling, allowing lower band gaps to be attained by mimicking molecular-wire behaviour. These gradually decreasing band-gap energies are responsible for the red-shifts observed in the steady-state absorption spectra, which are dependent on the conjugation length (Figure 1 and S1). By definition, electronic conduction in molecular wires occurs through molecular bridges, which chemically link an electron donor and acceptor, but remain electronically isolated from both moieties. These bridge orbitals are utilized solely as a coupling medium with no nuclear motion along the bridge. ${ }^{[20]}$

Therefore, it is not surprising that exchanging the phenyl within the donor moiety by a fluorene group, as is the case when comparing $\mathbf{B}$ with $\mathbf{C}$ or $\mathbf{D}$, has rather small effects on the energy levels. Specifically, it raises the HOMO energy by $0.06 \mathrm{eV}$ and, thus, minimizes the HOMO-LUMO gap by this value.

Through optimization of the electronic properties of the oxidized states of the dyes the long-range electronic coupling, which is mediated by the extended $\pi$-conjugation in these systems, can be improved. As observed, removing one electron from $\mathbf{A}$ leaves the electronic properties nearly unchanged. As seen from the orbital representations of the oxidized state in Figure S2, the LUMO of the oxidized state greatly resembles the electron density distribution of the HOMO in the neutral state. The energy decreases by $0.07 \mathrm{eV}$ when compared to the neutral HOMO. The situation, however, changes, when one electron is removed from B-D, molecules in which the $\pi$-conjugation length is significantly extended with respect to $\mathbf{A}$. The $\pi$-systems of $\mathbf{B}-\mathbf{D}$ are considerably perturbed, leading to a redistribution of electron density. Consequently, the LUMOs of the oxidized states (Figure S2) no longer closely resemble the HOMOs of the neutral counterparts (Figure 3 ) and their energies rise 
respectively by $0.33 \mathrm{eV}$ for $\mathbf{B}, 0.43 \mathrm{eV}$ for $\mathbf{C}$, and $0.80 \mathrm{eV}$ for $\mathbf{D}$. Furthermore, a significant portion of electron density is transferred onto the bridge, suggesting active participation of the bridge orbitals in the charge-transfer processes during the mediation of the electronic coupling between donor and acceptor. Remarkably, in $\mathbf{D}$, this electronic communication efficiently persists over a distance of nearly $30 \AA$.

The $\pi$-spacer in these $D-\pi$-A molecules promotes intramolecular charge-transfer separations through the bridge to the anchoring groups facilitating the electron injection into $\mathrm{TiO}_{2}$.

\section{Time-resolved spectroscopy}

As shown in the molecular modelling studies above, the frontier orbitals resemble the typical electronic distribution of a donor- $\pi$-spacer-acceptor system with the HOMO localized on the electron donating and the LUMO on the electron accepting part of the molecule. Thus, photoinduced excited-state formation will most likely be associated with a localized charge-transfer transition, which shifts electron density from the HOMO to the LUMO. To access the dynamics of those transitions in solution and the expected subsequent charge injection into $\mathrm{TiO}_{2}$, time-resolved spectroscopic techniques were employed. Investigations of the dyes adsorbed on transparent $3 \mu \mathrm{m}$ thick $\mathrm{TiO}_{2}$ films were performed.

Photoexcitation in solution results in a HOMO-to-LUMO charge transfer from the donor to the cyanoacrylic acid acceptor. The excited state adopts the form of an intramolecular radical ion pair. Characteristic spectral fingerprints evolve with a broad maximum in the region between 550 and $750 \mathrm{~nm}$ and a singlet bleaching in the region below $540 \mathrm{~nm}$, which overlaps with our $520 \mathrm{~nm}$ laser excitation. Another spectral feature maximizes at $450 \mathrm{~nm}$ for all of the compounds studied (Figure 4). The red maxima corresponds to the cation signatures of an oxidized triphenylamine when implemented into other similar $D-\pi-A$ compounds. ${ }^{[21]}$ The transient features redshift with the extension of the $\pi$-conjugation. For $\mathbf{A}$, the maximum of the newly formed transient is located around $550 \mathrm{~nm}$, whereas for $\mathbf{D}$ it shifts to $630 \mathrm{~nm}$. Even more interesting are the dynamics of the formation and deactivation of these excited states. The kinetics corresponding to single exponential fits of the time-absorption profiles at 570 and $630 \mathrm{~nm}$ are tabulated in Table 2. Regarding excited-state formation, $\mathbf{A}$ shows the fastest kinetics followed in decreasing order by C, B, and D. Following excitation the HOMO-to-LUMO charge transfer is expected to occur more quickly in A owing to the shortest donor-acceptor distances and the highest orbital overlap amongst the molecules investigated. The slightly slower kinetics of $\mathbf{B}$ relative to $\mathbf{C}$ may likely originate from a better stabilization of the positive charge on the donor site in $\mathbf{C}$. The larger size of the donor in $\mathbf{C}$ allows for improved spatial delocalization of the positive charge and increases the driving force for excited-state formation. The excited-state lifetimes likewise clearly depend on the length of the spacer between donor and acceptor. Hence, for A, recovery of the ground state occurs 6 times faster than for $\mathbf{D}$.

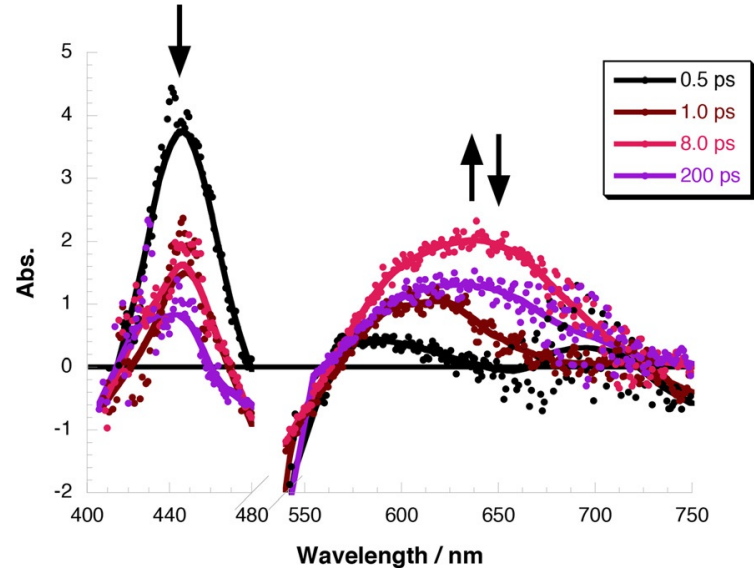

Figure 4. Representative femtosecond transient absorption $\left(\lambda_{\mathrm{exc}}=520 \mathrm{~nm}\right)$ spectra for the formation of the radical cation in a $0.1 \mathrm{~mm}$ chlorobenzene solution of $\mathbf{C}$. The arrows indicate the corresponding signals as mentioned in the text.

Table 2. Singlet excitation $\left(k_{\mathrm{S}}\right)$ and deactivation $\left(k_{\mathrm{D}}\right)$, charge injection $\left(k_{\mathrm{CI}}\right)$ and recombination $\left(k_{\mathrm{CR}}\right)$, and dye regeneration rate constants $\left(k_{\mathrm{DR}}\right)$ for $\mathrm{A}$ -

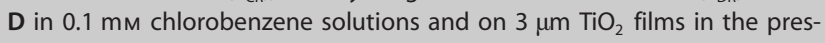
ence and absence of a redox electrolyte as obtained by transient absorption measurements on femto- and nano-second time scales with 520 and $500 \mathrm{~nm}$ light excitation, respectively.

\begin{tabular}{|c|c|c|c|c|}
\hline Dye & A & B & C & D \\
\hline \multicolumn{5}{|c|}{ chlorobenzene } \\
\hline$k_{\mathrm{s}}\left[\mathrm{s}^{-1}\right]$ & $2.02 \times 10^{12}$ & $7.80 \times 10^{11}$ & $8.35 \times 10^{11}$ & $7.24 \times 10^{11}$ \\
\hline$\tau_{1 / 2}[\mathrm{ps}]$ & 0.49 & 1.3 & 1.2 & 1.4 \\
\hline$k_{\mathrm{D}}\left[\mathrm{s}^{-1}\right]$ & $1.20 \times 10^{10}$ & $2.82 \times 10^{9}$ & $1.12 \times 10^{9}$ & $1.99 \times 10^{9}$ \\
\hline$\tau_{1 / 2}[\mathrm{ps}]$ & 83 & 357 & 471 & 503 \\
\hline \multicolumn{5}{|c|}{$\mathrm{TiO}_{2}$ no electrolyte } \\
\hline$k_{\mathrm{Cl}}\left[\mathrm{s}^{-1}\right]$ & $7.12 \times 10^{11}$ & $6.46 \times 10^{11}$ & $6.30 \times 10^{11}$ & $5.71 \times 10^{11}$ \\
\hline$\tau_{1 / 2}[\mathrm{ps}]$ & 1.4 & 1.6 & 1.6 & 1.8 \\
\hline$k_{\mathrm{CR}}\left[\mathrm{s}^{-1}\right]$ & $1.29 \times 10^{4}$ & $5.57 \times 10^{3}$ & $3.55 \times 10^{3}$ & $2.57 \times 10^{3}$ \\
\hline$\tau_{1 / 2}[\mu s]$ & 77 & 179 & 282 & 389 \\
\hline \multicolumn{5}{|c|}{$\mathrm{TiO}_{2}$ with electrolyte } \\
\hline$k_{\mathrm{DR}}\left[\mathrm{s}^{-1}\right]$ & $1.48 \times 10^{5}$ & $8.11 \times 10^{4}$ & $4.28 \times 10^{4}$ & $5.01 \times 10^{4}$ \\
\hline$\tau_{1 / 2}[\mu s]$ & 6.8 & 12 & 23 & 20 \\
\hline
\end{tabular}

Assuming that excited-state formation is associated with electron transfer through the $\pi$-spacer from the donor-localized HOMO to the acceptor-localized LUMO, and the deactivation is simply an intramolecular recombination process of the separated charges, the kinetics can be analysed as a function of donor-to-acceptor distance. The electronic coupling between the donor and acceptor is shown to have an exponential dependence $\left(k_{\mathrm{CT}}=k_{0} x \cdot \mathrm{e}^{-\beta r_{\mathrm{DA}}}\right)$, ${ }^{[22]}$ where $\beta$ is the so-called attenuation factor and $r_{\mathrm{DA}}$ is the distance between the donor and acceptor. Using this exponential dependence, we can treat the spacers as molecular wires and determine their charge transport properties. Accordingly, the slopes of the linear fits (Figure S3) of the rate constants as a function of donor-acceptor distance gave rise to a $\beta$ value of $0.05 \AA^{-1}$ for the intramolecular charge separation and $0.08 \AA^{-1}$ for the intramolecular charge recombination. $\beta$-values below $0.1 \AA^{-1}$ are in the range of highly conjugated oligo-phenylenevinylene molecular wires, 
confirming the highly conjugated nature of the VHP spacers, which are acting as molecular wires. ${ }^{[23]}$

In order to explore the role of the $\pi$-spacers-particularly their length-on the charge injection into $\mathrm{TiO}_{2}$, transient absorption measurements were also performed on $3 \mu \mathrm{m}$-thick dye-sensitized $\mathrm{TiO}_{2}$ films. When comparing to the solution studies the spectral features on $\mathrm{TiO}_{2}$ change slightly due to the intramolecular interactions on the surface. Moreover, the electronic coupling to the conduction band of $\mathrm{TiO}_{2}$ leads to an extension of the $\pi$-conjugated system into the nanoparticles, which in general broadens and slightly red shifts the transient signals. Hence, the radical cation maximum is found around $580 \mathrm{~nm}$ for $\mathbf{A}$ and $650 \mathrm{~nm}$ for B-D. The singlet bleaching is notably broadened resulting from solid-state interactions. Figure 5 represents the transient absorptions of the dye-sensitized $\mathrm{TiO}_{2}$ films of $\mathbf{A}$ and $\mathbf{D}$. Compared to $\mathbf{A}$, the red absorption maximum in $\mathbf{D}$ is shifted notably to lower energies resulting from the extension of the $\pi$-conjugation length. Interestingly, an isosbestic point appears in the spectrum of $\mathbf{D}$-a feature that is also found in $\mathbf{B}$ and $\mathbf{C}$. This phenomenon results from the different spatial distributions of HOMO and LUMO orbitals between $\mathbf{A}$ and $\mathbf{D}$ ( $\mathbf{B}$ and $\mathbf{C})$. The studies in chlorobenzene disclosed that owing to strong overlap of these two orbitals in $\mathbf{A}$, the singlet excitation occurs nearly three times faster than in the other dyes. As a consequence, the instantaneously generated singlet bleaching follows the same dynamics as the formation of the oxidized state of the dye owing to electron injection into $\mathrm{TiO}_{2}$. The considerably lower HOMO-LUMO gaps in B-D, on the other hand, stabilize their singlet-excited state, leading to considerably longer singlet lifetimes in solution. As a consequence, on $\mathrm{TiO}_{2}$ some of the photoexcited molecules of $\mathbf{B}-\mathbf{D}$ remain in the excited state without injecting electrons into the $\mathrm{TiO}_{2}$ surface. This leads to the initial partial drop of the maximum at $650 \mathrm{~nm}$ (Figure 5, right) within the first $200 \mathrm{ps}$ and the appearance of isosbestic points resulting from partial recovery of singlet bleaching. However, the majority of the investigated molecules inject electrons into $\mathrm{TiO}_{2}$, and the signals remain constant within the time-scale of our experimental setup (ca. $1 \mathrm{~ns}$ ).

Figure 6 displays the time absorption profiles at 570 and $650 \mathrm{~nm}$, which correspond to singlet bleaching and formation of the oxidized state of the dyes, respectively. Whereas both signals develop instantaneously and remain constant throughout the entire experimental time-scale for $\mathbf{A}$, the immediate appearance of both signals is followed by a drop in intensity within the first 200 ps for B-D. These observations are well in line with the above-mentioned interpretation of the transient absorption spectra.

Exponential fitting of the time-absorption profiles from spectra recorded within the first $4 \mathrm{ps}$ after photoexcitation (not shown) yielded the charge-injection rate constants, which are tabulated in Table 2. The rates show a similar dependence on the donor-to-acceptor distance as in the solution studies. However, resulting from adsorption on $\mathrm{TiO}_{2}$, the driving force (i.e., acceptor potential) for charge injection differs from the driving force for singlet excitation in solution. Hence, analysis of the distance dependence of the charge injection rate constant yielded an attenuation factor $\beta$ of $0.01 \AA^{-1}$. This suggests that the charge injection into $\mathrm{TiO}_{2}$ reveals nearly negligible dependence on the length of the linkers between the donor and acceptor, attesting to their remarkable molecular-wire behavior.

Considering the linkers as molecular wires (i.e., low $\beta$ value and invariant LUMO energies upon increasing length) the charge injection occurs nearly independent of distance and the rates will most likely depend on the orientation of the dye molecules on the $\mathrm{TiO}_{2}$ surface or the stabilization of the oxidized state owing to greater separation distance between the positive and negative charges. The second observation also involves the fact that the oxidized state may be stabilized by extending the $\pi$-conjugation of the donor, thereby giving the positive charge more space to delocalize. This explains why the charge injection in $\mathbf{C}$, where the positive charge can be symmetrically delocalized within the donor $\pi$-system, is faster than in B. Increasing stabilization of the oxidized state increas-
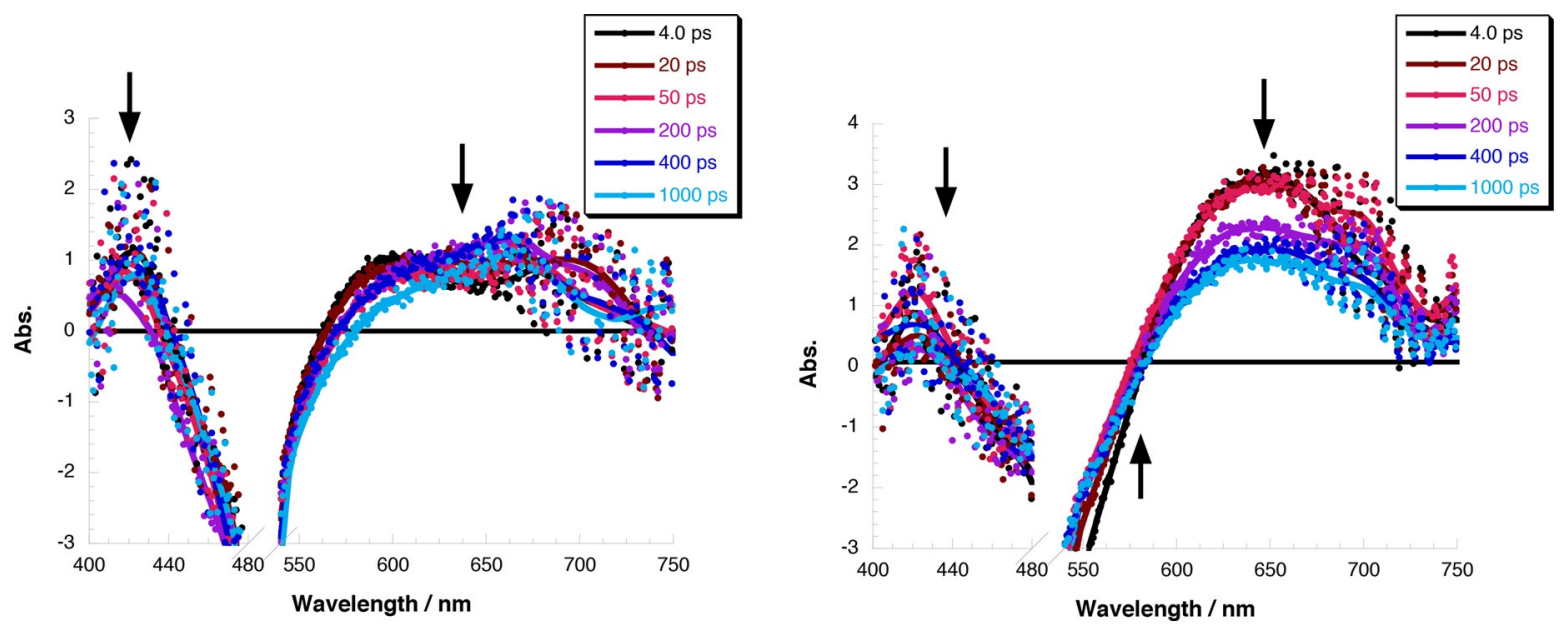

Figure 5. Femtosecond transient absorption $\left(\lambda_{\text {exc }}=520 \mathrm{~nm}\right.$ ) spectra for the formation of the radical cation in $3 \mu \mathrm{m}$ thick TiO ${ }_{2}$ films of $\mathbf{A}$ (left) and $\mathbf{D}$ (right). The arrows indicate the corresponding signals as mentioned in the text. 

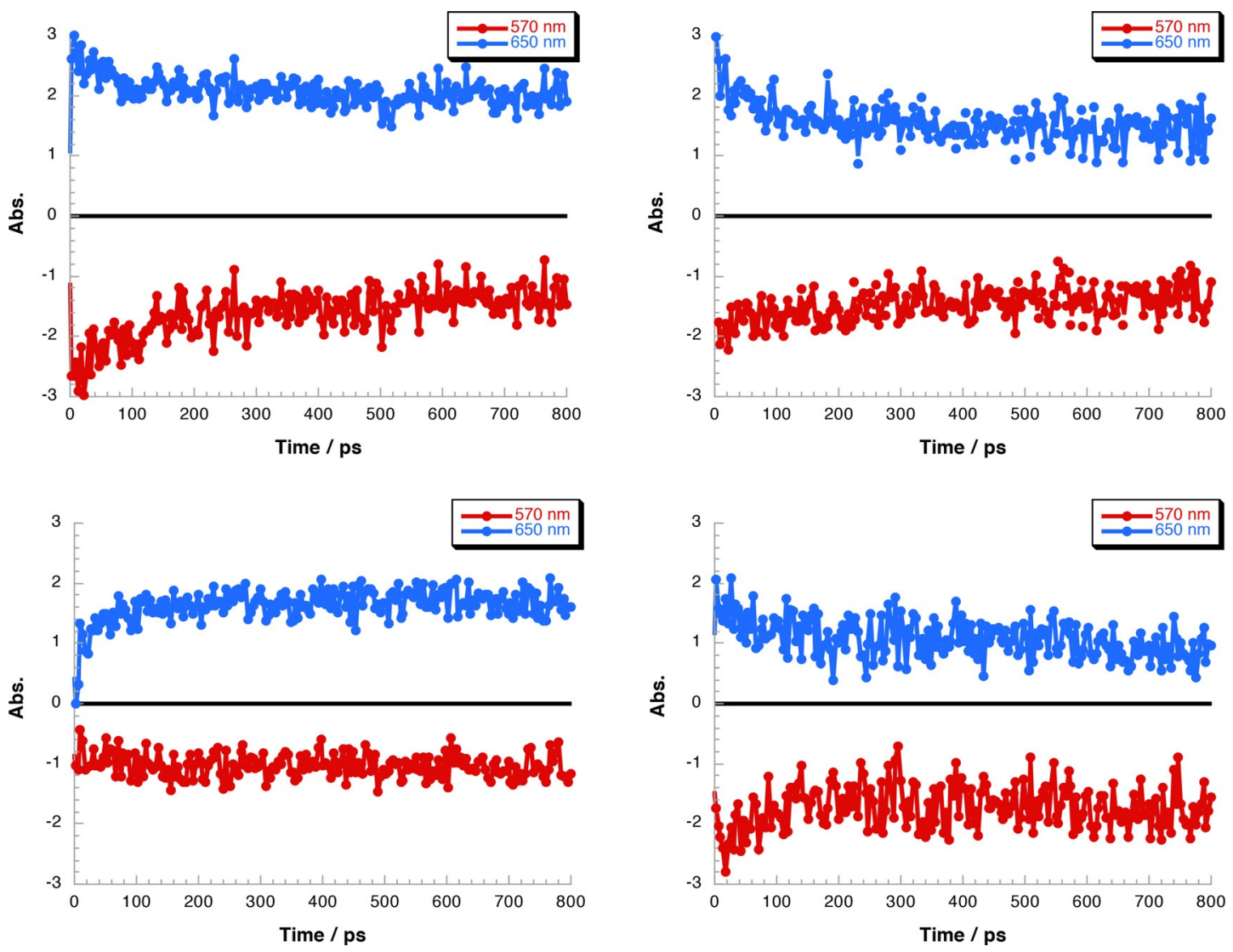

Figure 6. Time absorption profiles from femtosecond transient absorption ( $\lambda_{\text {exc }}=520 \mathrm{~nm}$ ) measurements of $\mathbf{A}$ (top left), B (top right), C (bottom left), and D (bottom right) on $3 \mu \mathrm{m}$ thick $\mathrm{TiO}_{2}$ films. The signal at $570 \mathrm{~nm}$ corresponds to the singlet bleaching and the $650 \mathrm{~nm}$ signature to the oxidized state of the dye.

es the driving force for charge transfer. Furthermore, the decoupling of HOMO and LUMO lowers the energy gap between both orbitals in B-D, which is reflected by the stabilization of their singlet excited states.

To scrutinize the fate of the oxidized states of the dyes, and study the dynamics of charge recombination between the injected electrons and the dye cation, nanosecond flash photolysis experiments were employed. The obtained transient spectra revealed identical spectral features as already described in the femtosecond studies, that is, transient bleach below $540 \mathrm{~nm}$ and a broad maximum from 550 to $750 \mathrm{~nm}$ (Figure 7).

The charge recombination was probed in the absence and in the presence of a redox electrolyte solution (Z960) by monitoring the decays of the spectral fingerprints of the oxidized states of the dyes at $680 \mathrm{~nm}$. In the absence of the electrolyte, the injected electrons recombine with the oxidized dye molecules on a time scale of one millisecond; the corresponding lifetimes and rate constants are given in Table 2 .

As seen from Table 2, the charge recombination half lives depends linearly on the distance between the donor and acceptor. From the rate constant versus distance relationship, it is possible to determine the attenuation factor $\beta$ for charge recombination. The obtained value is $0.08 \AA^{-1}$ (see Figure S4) and corresponds well with the attenuation factor for charge recombination in solution. Thus, it is safe to assume that the recombination occurs through back-electron transfer through the wire-like spacers and increasing their length retards the recombination process. In the presence of the redox electrolyte solution, deactivation of the oxidized state occurs nearly ten times faster (see Table 2), indicating that the reduction of the dye cation by the redox electrolyte is competing efficiently with charge recombination, that is, in a redox medium, dye regeneration occurs through the electrons from the electrolyte. However, the regeneration process also reveals a slight dependence on the structure of the dyes.

\section{Photovoltaic performances}

The photovoltaic parameters of the devices fabricated with dyes A-D in conjunction with volatile (Z960, see the Supporting Information for details regarding electrolyte compositions) and ionic liquid (Z952) electrolytes are presented in Table 3 and in Figure 8 (and Figure S5). Several general characteristics can be concluded about the performance of different dyes when examining the PCE of the devices with different electrolytes. First of all, the incident photon-to-power conversion efficiency (IPCE), and hence the short-circuit current density $\left(J_{\mathrm{SC}}\right)$, mirror the UV/Vis spectra showing a broad absorption from 400 to $650 \mathrm{~nm}$ for B-D and from 400 to $600 \mathrm{~nm}$ for dye A (see inset Figure 8). The integrated current from the IPCE recorded with a white bias light of about $5 \%$ intensity of one sun, complies well with the observed $J_{\text {SC }}$ values within about $5 \%$ devia- 

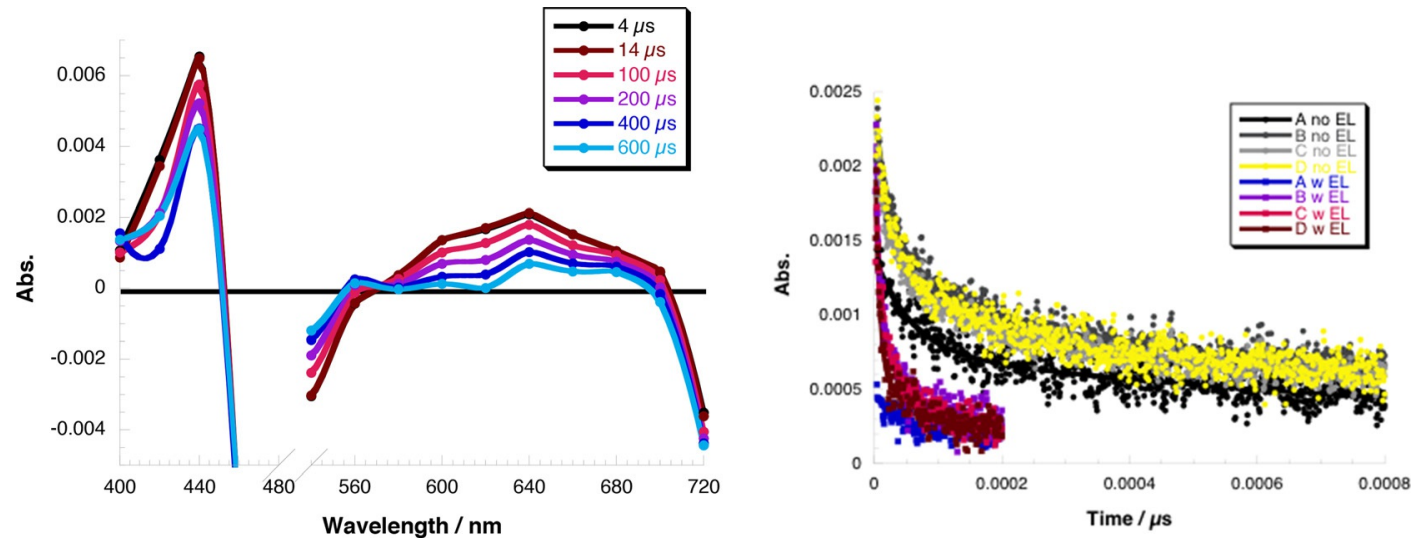

Figure 7. Representative transient absorption nanosecond flash photolysis spectrum $\left(\lambda_{\text {exc }}=500 \mathrm{~nm}\right)$ of $\mathrm{D}$ on $3 \mu \mathrm{m}$ mesoporous TiO ${ }_{2}$ in the absence of the redox electrolyte (left) and the time-absorption profiles at $680 \mathrm{~nm}$ of all dyes (right) with electrolyte (w EL) and without electrolyte (no EL).

\begin{tabular}{|c|c|c|c|c|c|}
\hline Electrolyte & Dye & $J_{\mathrm{SC}}\left[\mathrm{mAcm}^{-2}\right]$ & $V_{\mathrm{OC}}[\mathrm{mV}]$ & $\mathrm{FF}$ & PCE [\%] \\
\hline \multirow[t]{4}{*}{ Z952 } & A & 7.1 & 750 & 0.78 & 4.27 \\
\hline & B & 11.4 & 783 & 0.71 & 6.29 \\
\hline & $C$ & 11.1 & 770 & 0.72 & 6.17 \\
\hline & D & 8.5 & 690 & 0.74 & 4.44 \\
\hline \multirow[t]{4}{*}{ Z960 } & A & 8.1 & 751 & 0.76 & 4.71 \\
\hline & B & 12.9 & 767 & 0.66 & 6.42 \\
\hline & $C$ & 12.1 & 763 & 0.69 & 6.42 \\
\hline & D & 10.2 & 734 & 0.71 & 5.44 \\
\hline \multirow[t]{4}{*}{ Z1147 } & A & 7.6 & 840 & 0.72 & 4.71 \\
\hline & B & 11.7 & 931 & 0.62 & 6.98 \\
\hline & $C$ & 11.8 & 945 & 0.64 & 7.20 \\
\hline & D & 9.8 & 799 & 0.71 & 5.74 \\
\hline
\end{tabular}

tion. Interestingly, the $J_{\mathrm{SC}}$ for the devices with dye $\mathbf{D}$ is lower compared to $\mathbf{B}$ and $\mathbf{C}$ although the UV/Vis absorption shows the highest optical cross section for this dye. The device with dye $\mathbf{D}$ shows also a lower IPCE compared to $\mathbf{B}$ and $\mathbf{C}$. In general, several reasons can lead to such an effect: i) problems with the charge transport (this can be excluded owing to the white bias light of $5 \%$ of one sun), ii) mismatch of the redox potential of the electrolyte with the HOMO of the dye for dye regeneration or the hindered electron injection from the excited dye molecule into the conduction band of the $\mathrm{TiO}_{2}$ (determination of HOMO and LUMO levels of dye rule out this possibility), and the most probable reason, iii) low amount of dye adsorbed on the surface of the $\mathrm{TiO}_{2}$ film. With increasing dye molecular size, the dye loading on the surface of the $\mathrm{TiO}_{2}$ film will decrease, leading to lower absorption of photons and consequently to a lower $J_{\text {sc }}$.

Another obvious feature for discussion is the variation in the open-circuit voltage $\left(V_{\text {OC }}\right)$. Devices with dye $\mathbf{B}$ and $\mathbf{C}$ exhibit similar $V_{\text {OC }}$ values as shown in Table 3. Dye $\mathbf{A}$ results in a lower $V_{\text {OC }}$ compared to $\mathbf{B}$ and $\mathbf{C}$, but the lowest $V_{\text {OC }}$ is obtained for devices with dye $\mathbf{D}$. A shift of the $\mathrm{TiO}_{2}$ conduction-band edge or an increased recombination of electrons at the $\mathrm{TiO}_{2}$-electrolyte interface can be accountable for the lower $V_{\text {oc }}$ values. For
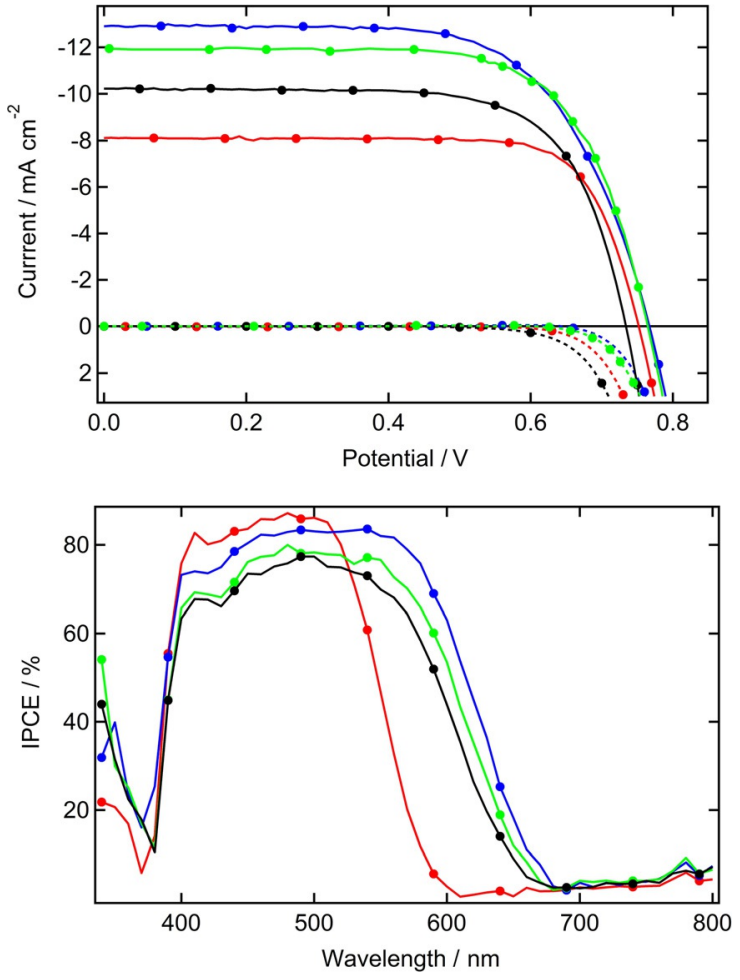

Figure 8. J-V characteristics (top) and the IPCE (bottom) of devices prepared using Z960. Color code: A: red; B: blue; C: green, D: black.

clarification, the devices were further investigated by electrochemical impedance spectroscopy (EIS).

\section{Electrochemical impedance measurements}

The main results of the EIS measurements are presented in Figure $9 \mathrm{a}$ (all analysis presented in the manuscript show the properties of the devices made with the $Z 960$ electrolyte; however, similar results were obtained with electrolytes Z952 and Z1147 and are presented in Figure S6 and S7). The parameters of the charge-transfer resistance at the $\mathrm{TiO}_{2}$-electrolyte interface $\left(R_{\mathrm{CT}}\right)$, the transport resistance for the electrons inside the 

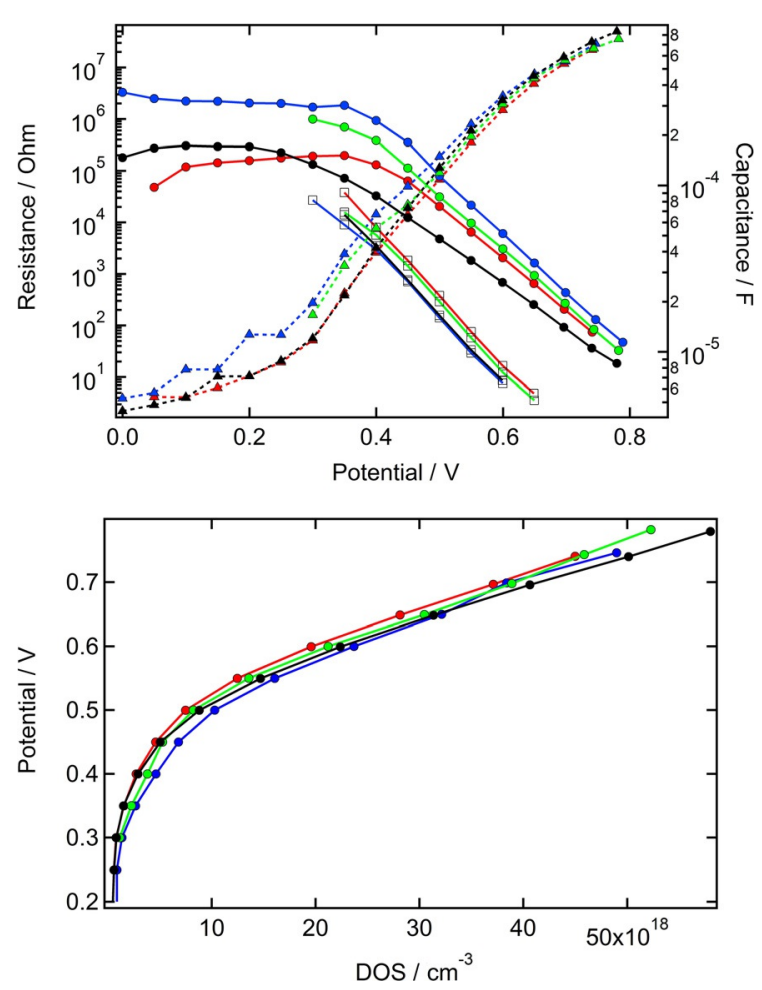

Figure 9. EIS analysis (top): transport resistance (empty squares), recombination resistance (filled circles), and chemical capacitance (triangles) of the $\mathrm{TiO}_{2}$ in a device prepared using Z960. DOS (bottom) calculated from the chemical capacitance of the mesoporous $\mathrm{TiO}_{2}$. Color code: A: red; B: blue; C: green, D: black.

$\mathrm{TiO}_{2}\left(R_{\text {trans }}\right)$, and the chemical capacitance of the mesoporous $\mathrm{TiO}_{2}\left(C_{\text {chem }}\right)$ were extracted based on the usage of the transmission-line model from EIS measurements. The behaviour of the chemical capacitance (Figure $9 \mathrm{a}$ ) or the density of states $\left(\mathrm{DOS}=6.24 \times 10^{18} \cdot C_{\mathrm{chem}} /[d(1-p)]\right)$; with $d$ being the thickness and $p$ being the porosity of the mesoporous $\mathrm{TiO}_{2}$ film; see Figure $9 b$ ) can give information on the relative change of the conduction band position of the $\mathrm{TiO}_{2}$ amongst the different devices. Generally it can be seen from EIS analysis that the change in conduction band position is small $(10-20 \mathrm{mV})$ for the four different device types, although the devices with dye D possess the lowest conduction-band position.

As a next step, the electron lifetime $\left(\tau_{\mathrm{n}}=R_{\mathrm{CT}} \times C_{\text {chem }}\right)$ can be observed and plotted against the DOS. This comparison gives a similar difference between the Fermi energy $\left(E_{\mathrm{F}}\right)$ and the conduction band in the different devices for similar values of the DOS.

In the three different electrolytes, the tendencies for all dyes are very similar regarding the electron lifetimes. The longest electron lifetimes were measured in the devices fabricated with dye B, followed by C, A, and D (Figures 10 and S7). Therefore, it is clear from the EIS measurements that the $V_{\text {OC }}$ for the devices with dye $\mathbf{D}$ should be lower compared to the other dyes owing to the lower-lying conduction band as well as the shorter electron lifetime. Devices made with dye A having a shorter electron lifetime and a lower $J_{\mathrm{SC}}$ show a slightly lower $V_{\mathrm{OC}}$ compared to $\mathbf{B}$ and $\mathbf{C}$ even though the conduction band

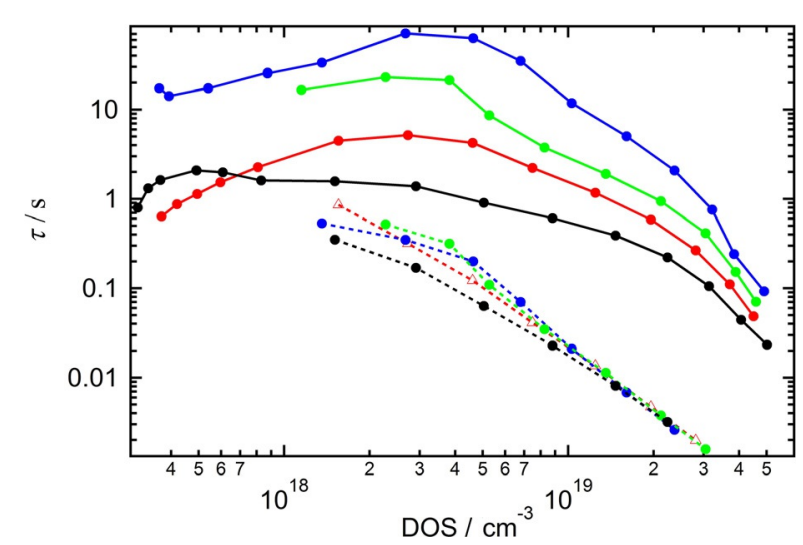

Figure 10. Electron lifetime (solid) and transport time (dotted) for devices prepared using the Z960 electrolyte. Color code: A: red; B: blue; C: green, D: black.

position is the highest amongst the devices. Devices with dye B show the longest electron lifetime amongst all dyes with only a slightly lower conduction band position and higher photocurrents. Thus $\mathrm{B}$ and $\mathrm{C}$ have the highest observed $V_{\mathrm{OC}}$.

\section{Conclusions}

This work examines four chemically and structurally related dyes by means of theoretical, photophysical, and electrochemical methods. The combination of the various analytical techniques helps in the understanding of the variations in the power conversion efficiency (PCE) of the solar cell devices fabricated with the different dyes. In concert with the photophysical studies and theory, the donor-spacer-acceptor chemical architecture, specific to these dyes governs their charge transfer properties. In particular the linker between the donor and acceptor moieties plays an important role in controlling charge injection and charge recombination kinetics. The structural variations in the dyes have a clear impact on the PCE of their respective devices. The analysis of the photovoltaic performances of the fabricated solar cell devices with various electrolytes complies very well with the photophysical investigations of the dye-sensitized $\mathrm{TiO}_{2}$ films.

Notably, by varying the distances between the donor and acceptor moieties of the molecules, a control over the charge injection and charge recombination rates can be maintained. On one hand, large separation distances with highly conjugated linkages between the donor and acceptor-as seen for dye $\mathbf{D}$-lead to longer lifetimes of the oxidized states of the dyes. On the other hand, bulky and conjugated donor moieties-as seen for dyes A, C, and D-have a similar retarding effect on the charge-recombination rate constant owing to stabilization of the positive charge upon improved delocalization. However, electrochemical impedance spectroscopy measurements disclose that, to fully understand the different efficiencies of the devices, one has to not only consider the chemical structure of the dyes but also the effects associated with the electrochemical features of the assembled devices. By probing electrolyte solutions with various redox couples, factors, such 
as conduction band levels versus redox potential of the electrolyte, dye loading, and/or the bulkiness of the dyes, were revealed and show that they play an important role in determining the final PCE.

It is the rather complex interplay between the effects of dye structure, electronic properties, molecular size and bulkiness, absorption coefficients, relation to the conduction band of $\mathrm{TiO}_{2}$, and recombination behavior that determines the photovoltaic performances of the devices.

\section{Acknowledgements}

MG thanks the Swiss National Science Foundation for financial support in the form of a Research Fellowship for MPA under the Indo-Swiss Joint Research programme. MW and JEM are grateful to NCCR MUST, a research instrument of the Swiss National Science Foundation. YSJ and KBY thank the Korea Center for Artificial Photosynthesis (KCAP) funded by the Minister of Science, ICT and Future Planning (MSIP) through the National Research Foundation of Korea (No. 2009-0093886) for financial support. SN and MPA acknowledge The Government of India Department of Science and Technology for their support and for providing travel support to MPA under the Indo-Swiss fellowship program.

Keywords: conjugation length • donor-acceptor • dyesensitized solar cells · energy conversion · sensitizers

[1] M. Grätzel, Nature 2001, 414, 338-344.

[2] Z. Yao, M. Zhang, H. Wu, L. Yang, R. Li, P. Wang, J. Am. Chem. Soc. 2015, 137, 3799-3802.

[3] S. Mathew, A. Yella, P. Gao, R. Humphry-Baker, B. F. E. Curchod, N. Ashari-Astani, I. Tavernelli, U. Rothlisberger, M. K. Nazeeruddin, M. Grätzel, Nat. Chem. 2014, 6, 242-247.

[4] K. R. J. Thomas, J.T. Lin, Y.-C. Hsu, K.-C. Ho, Chem. Commun. 2005, $4098-4100$.

[5] Z. S. Wang, Y. Cui, Y. Dan-Oh, C. Kasada, A. Shinpo, K. Hara, J. Phys. Chem. C 2008, 112, $17011-17017$.

[6] a) W. Wu, J. Zhang, H. Yang, B. Jin, Y. Hu, J. Hua, C. Jing, Y. Long, H. Tian, J. Mater. Chem. 2012, 22, 5382-5389; b) Y. Mizuno, Y. Yisilamu, T. Yamaguchi, M. Tomura, T. Funaki, H. Sugihara, K. Ono, Chem. Eur. J. 2014, 20 13286-13295; c) M. Liang, J. Chen, Chem. Soc. Rev. 2013, 42, $3453-$ 3488.

[7] a) T. Horiuchi, H. Miura, K. Sumioka, S. Uchida, J. Am. Chem. Soc. 2004, 126, 12218-12219; b) S. Higashijima, Y. Inoue, H. Miura, Y. Kubota, K. Funabiki, T. Yoshida, M. Matsui, RSC Adv. 2012, 2, 2721-2724; c) Y. Wu, W. Zhu, Chem. Soc. Rev. 2013, 42, 2039-2058; d) Q. Chai, W. Li, J. Liu, Z. Geng, H. Tian, W. Zhu, Sci. Rep. 2015, 5, 11330; e) K. Pei, Y. Wu, H. Li, Z. Geng, H. Tian, W. Zhu, ACS Appl. Mater. Interfaces 2015, 7, 5296-5304.
[8] a) K. Hara, M. Kurashige, Y. Dan-oh, C. Kasada, A. Shinpo, S. Suga, K. Sayama, K. Arakawa, New J. Chem. 2003, 27, 783-785; b) K. Hara, K. Sayama, Y. Ohga, A. Shinpo, S. Suga, H. Arakawa, Chem. Commun. 2001, 569-570; c) K. Hara, Y. Tachibana, Y. Ohga, A. Shinpo, S. Suga, K. Sayama, H. Sugihara, H. Arakawa, Sol. Energy Mater. Sol. Cells 2003, 77, 89-103; d) K. Hara, Z.-S. Wang, T. Sato, A. Furube, R. Katoh, H. Sugihara, Y. Dan-oh, C. Kasada, A. Shinpo, S. Suga, J. Phys. Chem. B 2005, 109, 15476-15482; e) K. Hara, K. Miyamoto, Y. Abe, M. Yanagida, J. Phys. Chem. B 2005, 109, 23776-23778; f) K. Hara, T. Sato, R. Katoh, A. Furube, Y. Ohga, A. Shinpo, S. Suga, K. Sayama, H. Sugihara, H. Arakawa, J. Phys. Chem. B 2003, 107, 597-606; g) Z.-S. Wang, Y. Cui, Y. Dan-oh, C. Kasada, A. Shinpo, K. Hara, J. Phys. Chem. C 2007, 111, 7224-7230.

[9] W. M. Campbell, K. W. Jolley, P. Wagner, K. Wagner, P. J. Walsh, K. C. Gordon, L. Schmidt-Mende, M. K. Nazeeruddin, Q. Wang, M. Grätzel, J. Phys. Chem. C 2007, 111, 11760-11762.

[10] a) X. Liu, J. Long, G. Wang, Y. Pei, B. Zhao, S. Tan, Dyes Pigm. 2015, 121, 118-127; b) Y. Hua, S. Chang, D. Huang, X. Zhou, X. Zhu, J. Zhao, et al., Chem. Mater. 2013, 25, 2146-2153.

[11] a) C.-J. Yang, Y. J. Chang, M. Watanabe, Y.-S. Hon, T. J. Chow, J. Mater. Chem. 2012, 22, 4040-4049; b) J. Li, W. Wu, J. Yang, J. Tang, Y. Long, J. Hua, Sci. China Chem. 2011, 54, 699-706; c) W. Wu, J. Yang, J. Hua, J. Tang, L. Zhang, Y. Long, H. Tian, J. Mater. Chem. 2010, 20, 1772-1779.

[12] Y. J. Chang, P.-T. Chou, Y.-Z. Lin, M. Watanabe, C.-J. Yang, T.-M. Chin, T. J. Chow, J. Mater. Chem. 2012, 22, 21704-21712.

[13] Z. Wan, C. Jia, Y. Duan, L. Zhou, Y. Lin, Y. Shi, J. Mater. Chem. 2012, 22, $25140-25147$.

[14] M. J. Kim, Y. J. Yu, J. H. Kim, Y. S. Jung, K. Y. Kay, S. B. Ko, C. R. Lee, I. H. Jang, Y. U. Kwon, N. G. Park, Dyes Pigm. 2012, 95, 134-141.

[15] a) N. G. Connelly, W. E. Geiger, Chem. Rev. 1996, 96, 877-910; b) P. Winget, C. J. Cramer, D. G. Truhlar, Theor. Chem. Acc. 2004, 112, 217 227.

[16] P. J. Stephens, F. J. Devlin, C. F. Chablowski, M. Frisch, J. Phys. Chem. 1994, 98, $11623-11627$.

[17] V. A. Rassolov, J. A. Pople, M. A. Ratner, T. L. Windus, J. Chem. Phys. 1998, 109, $1223-1229$.

[18] M. J. Frisch, et al., Gaussian, Inc., Wallingford CT, 2009.

[19] W. B. Davis, W. A. Svec, M. A. Ratner, M. R. Wasielewski, Nature 1998, $396,60-63$

[20] A. Nitzan, M. A. Ratner, Science 2003, 300, 1384-1389.

[21] a) M. Oyama, T. Higuchi, S. Okazaki, Electrochem. Solid-State Lett. 2002, 5, E1-E3; b) S. Fantacci, F. De Angelis, M. K. Nazeeruddin, M. Grätzel, J. Phys. Chem. C 2011, 115, 23126-23133; c) J. R. Pinzón, D. Gasca, S. Gayathri, G. Bottari, T. Torres, D. M. Guldi, L. Echegoyen, J. Am. Chem. Soc. 2009, 131, 7727-7734.

[22] Top. Curr. Chem. (Ed.: L. De Cola) 2005, 257, Springer, Berlin, 63-103.

[23] a) P. A. Van Hal, S. C. J. Meskers, R. A. Janssen, J. Appl. Phys. A 2004, 79, $41-46$; b) G. de la Torre, F. Giacalone, J. L. Segura, N. Martin, D. M. Guldi, Chem. Eur. J. 2005, 11, 1267-1280; c) T. M. Figueira-Duarte, A. Gégout, J. F. Nierengarten, Chem. Commun. 2007, 109-119; d) T. L. J. Toivonen, T. I. Hukka, J. Phys. Chem. A 2007, 111, 4821-4828; e) J. Santos, B. M. IIIescas, M. Wielopolski, A. M. G. Silva, A. C. Tomé, D. M. Guldi, N. Martín, Tetrahedron 2008, 64, 11404-11408.

Received: July 10, 2015

Revised: August 24, 2015

Published online on October 13, 2015 


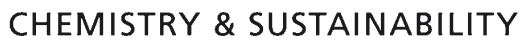 \\ CHEMSUSCHEM}

ENERGY \& MATERIALS

\section{Supporting Information}

\section{Long-Range $\pi$-Conjugation in Phenothiazine-containing Donor-Acceptor Dyes for Application in Dye-Sensitized Solar Cells}

Mini P. Antony, ${ }^{[a, b]}$ Thomas Moehl, ${ }^{[a]}$ Mateusz Wielopolski, ${ }^{[c]}$ Jacques-E. Moser, ${ }^{[c]}$ Shantikumar Nair, ${ }^{[b]}$ Yong-Jae Yu, ${ }^{[d]}$ Jong-Hyung Kim, ${ }^{[d]}$ Kwang-Yol Kay, ${ }^{*[d, ~ e] ~ Y o u n g-~}$ Sam Jung, ${ }^{[f]}$ Kyung Byung Yoon, ${ }^{[f]}$ Carole Grätzel, ${ }^{[a]}$ Shaik M. Zakeeruddin, ${ }^{*[a]}$ and Michael Grätzel*[a] 


\section{Experimental}

\section{Materials and instruments}

Reagents and solvents were purchased as reagent grade and used without further purification. All reactions were performed using dry glassware under nitrogen atmosphere. Analytical TLC was carried out on Merck 60 F254 silica gel plate and column chromatography was performed on Merck 60 silica gel (230-400 mesh).

7-Bromo-10-hexyl-10H-3-phenothiazine carboxaldehyde (4) and 7[\{7-bromo-10-hexyl-10Hphenothiazine-3-yl\} vinyl]-10-hexyl-10H-phenothiazine -3-carboxaldehyde (9) were prepared according to our previous report. ${ }^{1)}$ The model compound A was also synthesized by the reaction of 4-[N, N-bis(9, 9-dimethylfluoren-2-yl)amino]benzaldehyde with cyanoacetic acid according to literature method. ${ }^{2)}$ Vinyl group in compounds $\mathbf{5}$ and $\mathbf{7}$ were easily introduced through Wittig reaction of corresponding aldehydes. ${ }^{2)}$

Melting points were determined on an Electrothermal IA 9000 series melting point apparatus and are uncorrected. NMR spectra were recorded on a Varian Mercury-400 (400 $\mathrm{MHz}$ ) spectrometer with TMS peak as reference. UV/vis spectra were recorded on a Jasco V550 spectrometer. MALDI-TOF MS spectra were recorded with an Applied Biosystems Voyager-DE-STR. Elemental analyses were performed with a Perkin-Elmer 2400 analyzer.

\section{Time-resolved laser studies}

Time-resolved pump-probe transient absorption measurements were performed on the dye-sensitized, $3 \mu \mathrm{m}$-thick, transparent $\mathrm{TiO}_{2}$ films in the presence and absence of the electrolyte Z960. For solution studies $1 \mathrm{~mm}$ quartz cuvettes have been employed.

The pump-probe technique uses a compact CPA-2001, $1 \mathrm{kHz}$, Ti: Sapphire-amplified femtosecond laser (Clark-MXR), with a pulse width of about $120 \mathrm{fs}$ and a pulse energy of $1 \mathrm{~mJ}$ at a central wavelength of $775 \mathrm{~nm}$. The output beam was split into two parts for pumping a double-stage noncollinear optical parametric amplifier (NOPA) and to produce a white light continuum in a sapphire plate or $387 \mathrm{~nm}$ UV light by second harmonic generation of the CPA output in a thin BBO crystal. The NOPA was pumped by $200 \mu \mathrm{J}$ pulses at a central wavelength of $775 \mathrm{~nm}$, and the excitation wavelength was tuned to $520 \mathrm{~nm}$ to generate pulses of approximately $10 \mu \mathrm{J}$. The output pulses of the NOPA were compressed in a SF10-glass prism pair compressor down to a duration of approximately $60 \mathrm{fs}$ (fwhm). Iris diaphragms were used to decrease the pulse energy down to a few micro joules for the pump and to less than $1 \mu \mathrm{J}$ for the probe beam. Transient spectra were measured using a white light continuum (WLC) for probing. 
The nanosecond laser flash photolysis employed 7 ns pulses to excite the sample at $\lambda=$ $520 \mathrm{~nm}$ with a $30 \mathrm{~Hz}$ repetition rate. A Powerlite 7030 frequency-doubled Q-switched Nd:YAG laser (Continuum, Santa Clara, California, USA) served as a light source. The laser beam output was expanded by a plano-concave lens to irradiate a large crosssection of the sample, whose surface was kept at a $40^{\circ}$ angle to the excitation beam. The laser fluence on the sample was kept at a low level $\left(40 \mu \mathrm{J} \mathrm{cm}^{-2}\right.$ per pulse) to ensure that, on average, less than one electron is injected per $\mathrm{TiO}_{2}$ nano-particle on exposure to one laser pulse. The probe light, produced by a continuous wave xenon arc lamp, was first passed through a monochromator tuned between 400 and $720 \mathrm{~nm}$, various optical elements, the sample, and then through a second monochromator, before being detected by a fast photomultiplier tube (Hamamatsu, R9110).

\section{Device fabrication}

A screen-printed double layer film of mesoporous $\mathrm{TiO}_{2}$ was used to sensitize the films as photoanode. 8 or $4 \mu \mathrm{m}$ thick transparent film of $20 \mathrm{~nm}$ sized $\mathrm{TiO}_{2}$ particles was first printed on the fluorine-doped $\mathrm{SnO}_{2}$ (FTO) conducting glass and further coated by a $5 \mu \mathrm{m}$ thick second layer of $400 \mathrm{~nm}$-sized light scattering anatase particles. The DSC devices were fabricated using four dyes (A-D), in conjunction with 3 electrolytes (Z960, Z952, Z1147). The photoanode $(8+5 \mu \mathrm{m}$ is applied for Z960 and Z952 electrolytes and $4+5$ is applied for Z1147 electrolyte) was prepared by immersing double layer $\mathrm{TiO}_{2}$ film into the dye solution for $8 \mathrm{~h}$ at room temperature in the dye solution $(150 \mu \mathrm{M})$ in chlorobenzene. Thermally platinized FTO glass counter electrode and dye-sensitized $\mathrm{TiO}_{2}$ electrode was assembled into device by sealing it with a $25 \mu \mathrm{m}$ thick hot-melt film (Surlyn). The electrolyte was filled up in the device through the pre-drilled holes in the counter electrodes and the device fabrication was completed by sealing the holes with a Surlyn sheet followed by heat mounting of a thin glass cover.

\section{Photovoltaic performance measurements}

The set-up used for conducting standard photovoltaic characterization (J-V curve) consists of a $450 \mathrm{~W}$ xenon lamp (Oriel), whose spectral output was matched in the region of 350-750 $\mathrm{nm}$ with the aid of a Schott K113 Tempax sunlight filter (PräzisionsGlas\&Optik GmbH), and a source meter Keithley 2400 (Keithley) to apply potential bias and measure the photogenerated current. A set of metal-mesh filters was 
used to adjust the light intensity to desired levels. IPCE was measured using a similar set-up; however, the incident light (300 W xenon lamp, ILC Technology) was focused through a Gemini-180 double monochromator (Jobin-Yvon Ltd.). The cells were measured with an external light bias ( $5 \%$ Sun) provided by a LED array.

\section{DPV and Impedance measurements}

The differential pulse voltammetry (DPV) measurements were carried out in $\mathrm{CH}_{2} \mathrm{Cl}_{2}$ with 0.1 $\mathrm{M} \mathrm{TBAPF}_{6}$ as conduction salt and with a Pt wires serving as working, counter and reference electrode. The reference potential was calibrated over Ferrocene $\left(\mathrm{FC} / \mathrm{FC}^{+}=701 \mathrm{mV}\right.$ vs SHE$)$. EIS measurements were performed by a Biologic SP300 (BioLogic, France) in a frequency range between $7 \mathrm{MHz}$ and $0.1 \mathrm{~Hz}$ for potentials between $0 \mathrm{~V}$ to about $\mathrm{V}_{\mathrm{OC}}$ (with a $20 \mathrm{mV}$ sinusoidal AC perturbation) in $50 \mathrm{mV}$ steps. The resulting impedance spectra were analyzed with the ZView software (Scribner Associate). The potential of the EIS results are corrected for IR-Drop. The real potential ( $\left.V_{\text {real }}\right)$ is determined by the subtraction of the voltage drop ( $\left.V_{\text {Drop }}\right)$ from the applied potential ( $\left.V_{\text {applied }}\right)$. The voltage drop is calculated by the integration of the sum of all series resistances $\left(R_{\text {Aseries }}\right)$ over the current passed. ( $V_{\text {real }}=V_{\text {applied }}-V_{\text {Drop }}$; with $V_{\text {Drop }}=\int R_{\text {Aseries }} \mathrm{dI}$ whereby $\left.R_{\text {Aseries }}=R_{\mathrm{S}}+R_{\text {ce }}+R_{\text {Electrolyte }}\right)$. 


\section{Synthesis}
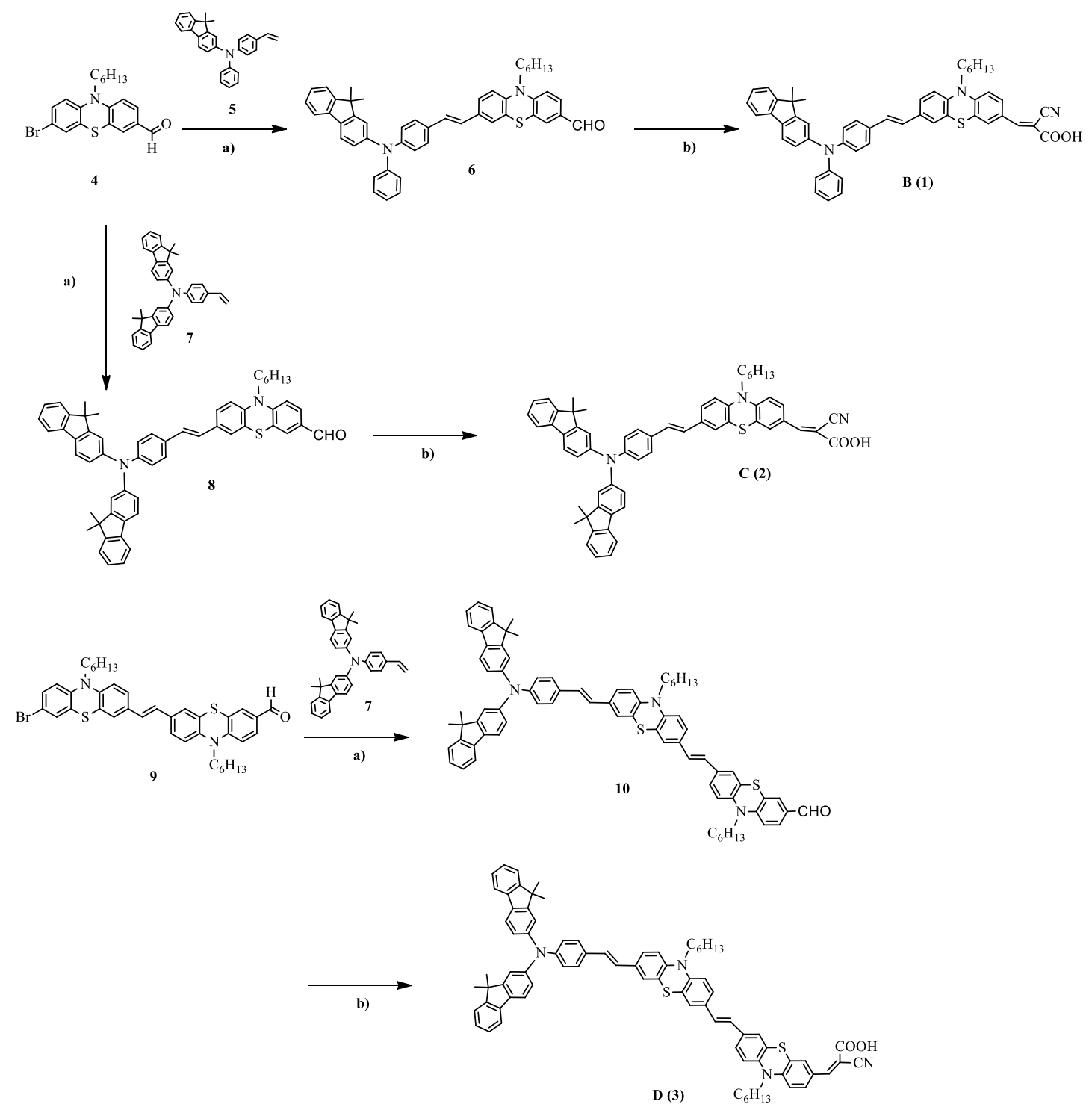

Scheme 1 Synthesis of $\mathbf{B}(1), \mathbf{C}(2)$ and $\mathbf{D}(3)$; a) compound $\mathbf{5}, \mathrm{Pd}(\mathrm{OAc})_{2}, \mathrm{Bu}_{4} \mathrm{NBr}$, $\mathrm{K}_{2} \mathrm{CO}_{3}, \mathrm{DMF}, 105^{\circ} \mathrm{C}, 16 \mathrm{~h}, 62.5 \%$ for $\mathbf{6}$, compound $7,64.5 \%$ for 8 , compound 7 , $55.3 \%$ for 10 . b) cyanoacetic acid, piperidine, chloroform, reflux, $16 \mathrm{~h}, 78.1 \%$ for $\mathbf{1}$, $61.8 \%$ for $2,25.5 \%$ for 3

N-(9,9-Dimethylfluoren-2-yl)-N-phenyl-4-vinylaniline (5). To a mixture of $\mathrm{CH}_{3} \mathrm{PPh}_{3} \mathrm{Br}(707 \mathrm{mg}, 1.97 \mathrm{mmol})$ and $\mathrm{NaH}(60 \mathrm{mg}, 2.50 \mathrm{mmol})$ in anhydrous $\mathrm{THF}$ (20 ml) was added 7-bromo-10-hexyl-10H-3-phenothiazine carboxaldehyde (645 mg, $1.65 \mathrm{mmol}$ ), and stirred at $40^{\circ} \mathrm{C}$ for 24 hours. The reaction mixture was treated with 
methanol $(10 \mathrm{ml})$ and then with water $(50 \mathrm{ml})$, and extracted with dichloromethane $(3 \times 50 \mathrm{ml})$. The organic extracts were dried over $\mathrm{Na}_{2} \mathrm{SO}_{4}$ and the solvent was evaporated under reduced pressure. The crude product was chromatographed on silica gel with dichloromethane/hexane (1:2) to give 5 as a yellowish solid (479 $\mathrm{mg}$, 74.9\%). ${ }^{1} \mathrm{H}$ NMR (400 MHz, $\left.\mathrm{CDCl}_{3}\right): \delta=7.62(\mathrm{~d}, 1 \mathrm{H}), 7.57(\mathrm{~d}, 1 \mathrm{H}), 7.37(\mathrm{~d}, 1 \mathrm{H}), 7.29$ (d,1H), $7.27(\mathrm{t}, 1 \mathrm{H}), 7.24(\mathrm{~d}, 2 \mathrm{H}), 7.23(\mathrm{~d}, 2 \mathrm{H}), 7.19(\mathrm{~s}, 1 \mathrm{H}), 7.14(\mathrm{~d}, 2 \mathrm{H}), 7.07(\mathrm{~d}, 2 \mathrm{H}), 7.03$ $(\mathrm{q}, 3 \mathrm{H}), 5.61(\mathrm{~d}, 1 \mathrm{H}), 5.18(\mathrm{~d}, 1 \mathrm{H}), 1.41(\mathrm{~s}, 6 \mathrm{H})$. Anal. Calcd (\%) for $\mathrm{C}_{27} \mathrm{H}_{25} \mathrm{~N}$ : C 89.21, H 6.93, N 3.85. Found: C 88.93, H 7.18, N 3.89.

\section{7-\{4-(9, 9-dimethyl-9H-fluoren-2-yl-phenylamino)styryl $\}$-10-hexyl-10H-} phenothiazine-3-carboxaldehyde (6). To a solution of compound 5 (500 mg, 1.29 $\mathrm{mmol})$ and compound 4 (503 $\mathrm{mg}, 1.29 \mathrm{mmol})$ in DMF $(20 \mathrm{~mL})$ were added $\mathrm{Pd}(\mathrm{OAc})_{2}$ (57 mg $0.21 \mathrm{mmol}), \mathrm{Bu}_{4} \mathrm{NBr}(831 \mathrm{mg}, 2.57 \mathrm{mmol})$ and $\mathrm{K}_{2} \mathrm{CO}_{3}(621 \mathrm{mg}, 5.15 \mathrm{mmol})$. The mixture was stirred at $105{ }^{\circ} \mathrm{C}$ for $16 \mathrm{~h}$. After cooling, the solution was poured into water $(50 \mathrm{~mL})$ and the crude products were extracted with dichloromethane $(3 \times$ $50 \mathrm{~mL}$ ). The combined organic extract was dried over $\mathrm{Na}_{2} \mathrm{SO}_{4}$, and the solvent was removed under reduced pressure. The residue was chromatographed on silica gel with dichloromethane/hexane (1:2) to produce compound 6 (562 $\mathrm{mg}, 62.5 \%)$ in a yellowish solid. M.p. $67{ }^{\circ} \mathrm{C} .{ }^{1} \mathrm{H}$ NMR $\left(400 \mathrm{MHz}, \mathrm{CDCl}_{3}\right): \delta=9.71(\mathrm{~s}, 1 \mathrm{H}), 7.50-7.57$ $(\mathrm{m}, 4 \mathrm{H}), 7.18-7.32(\mathrm{~m}, 11 \mathrm{H}), 7.02-7.14(\mathrm{~m}, 5 \mathrm{H}), 6.75-6.87(\mathrm{~m}, 4 \mathrm{H}), 3.81(\mathrm{t}, 2 \mathrm{H})$, $1.75(\mathrm{~m}, 2 \mathrm{H}), 1.34(\mathrm{~s}, 8 \mathrm{H}), 1.24-1.26(\mathrm{~m}, 4 \mathrm{H}), 0.76-0.83(\mathrm{~m}, 3 \mathrm{H})$. Anal. Calcd (\%) for $\mathrm{C}_{48} \mathrm{H}_{44} \mathrm{~N}_{2} \mathrm{OS}$ : C, 82.72; H, 6.36; N, 4.02. Found: C 82.46, H 6.51, N 3.86

\section{3-[7-[\{4-N(9,9-dimethyl-9H-fluoren-2-yl-phenylamino)phenylaminostyryl $\}]-10-$ hexyl-10H-phenothiazin-3-yl]-2-cyanoacrylic acid (1).}

A mixture of compound $6(400 \mathrm{mg}, 0.54 \mathrm{mmol})$ and cyanoacetic acid (488 mg, 5.4 mmol $)$ in dry chloroform $(30 \mathrm{~mL})$ was refluxed in the presence of piperidine $(1 \mathrm{ml})$ for $16 \mathrm{~h}$. After cooling, the solution was poured into water $(50 \mathrm{~mL})$ and the crude product was extracted with chloroform $(3 \times 50 \mathrm{~mL})$. The combined organic extracts were dried over $\mathrm{Na}_{2} \mathrm{SO}_{4}$, and the solvent was removed under reduced pressure. The crude product was chromatographed on silica gel with dichloromethane/MeOH (10 : 1) to give compound 1 (322 mg, 78.1\%) in a red solid. M.p. $103{ }^{\circ} \mathrm{C} .{ }^{1} \mathrm{H}$ NMR (400 MHz, DMSO-d $\left.{ }_{6}\right): \delta=7.96(\mathrm{~s}, 1 \mathrm{H}), 7.80(\mathrm{~d}, J=8.4 \mathrm{~Hz}, 1 \mathrm{H}), 7.71-7.74(\mathrm{~m}, 3 \mathrm{H}), 7.46-$ $7.50(\mathrm{~m}, 3 \mathrm{H}), 7.22-7.37(\mathrm{~m}, 7 \mathrm{H}), 6.95-7.13(\mathrm{~m}, 10 \mathrm{H}), 3.91(\mathrm{t}, 2 \mathrm{H}), 1.68(\mathrm{~m}, 2 \mathrm{H}), 1.36$ 
(s, 8H), $1.24(\mathrm{~m}, 4 \mathrm{H}), 0.82(\mathrm{t}, 3 \mathrm{H})$. Anal. Calcd (\%) for $\mathrm{C}_{51} \mathrm{H}_{45} \mathrm{~N}_{3} \mathrm{O}_{2} \mathrm{~S}: \mathrm{C}, 80.18 ; \mathrm{H}$, 5.94; N, 5.50. Found: C 80.02, H 6.02, N 5.32.

\section{N, N-Bis(9,9-dimethylfluoren-2-yl)-4-vinylaniline (7).}

To a mixture of $\mathrm{CH}_{3} \mathrm{PPh}_{3} \mathrm{Br}(900 \mathrm{mg}, 2.51 \mathrm{mmol})$ and $\mathrm{NaH}(75 \mathrm{mg}, 3.12 \mathrm{mmol})$ in anhydrous THF (20 ml) was added 4-[N, N-bis(9,9-dimethylfluoren-2yl)amino]benzaldehyde $(1.10 \mathrm{~g}, 2.17 \mathrm{mmol})$, and stirred at $40^{\circ} \mathrm{C}$ for 24 hours. The reaction mixture was treated with methanol $(10 \mathrm{ml})$ and then with water $(50 \mathrm{ml})$, and extracted with dichloromethane $(3 \times 50 \mathrm{ml})$. The organic extracts were dried over $\mathrm{Na}_{2} \mathrm{SO}_{4}$ and the solvent was evaporated under reduced pressure. The crude product was chromatographed on silica gel with dichloromethane/hexane (1:2) to give 7 as a yellowish solid (765 mg, 72.8\%). ${ }^{1} \mathrm{H}$ NMR (400 MHz, $\left.\mathrm{CDCl}_{3}\right): \delta=7.64(\mathrm{~d}, 2 \mathrm{H}), 7.59$ (d, 2H), 7.39 (d, 2H), $7.33(\mathrm{~d}, 2 \mathrm{H}), 7.29(\mathrm{t}, 2 \mathrm{H}), 7.27(\mathrm{t}, 2 \mathrm{H}), 7.23(\mathrm{~s}, 2 \mathrm{H}), 7.13(\mathrm{~d}, 2 \mathrm{H}), 7.06$ $(d, 2 H), 6.7(q, 1 H), 5.61(d, 1 H), 5.18(d, 1 H), 1.57(s, 12 H)$. Anal. Calcd $(\%)$ for $\mathrm{C}_{38} \mathrm{H}_{33} \mathrm{~N}$ : C, 90.61; H, 6.60; N, 2.78. Found: C 90.32, H 6.82, N 2.86.

\section{7-\{4-(bis(9,9-dimethylfluoren-2-yl)amino)styryl\}-10-hexyl-10H-phenothiazine-3-}

carboxaldehyde (8). Compound 8 was synthesized using compound 7 by the similar method described for 6.8 (486 mg, 64.5\% yield), yellowish solid. M.p. 86 ${ }^{\circ} \mathrm{C} .{ }^{1} \mathrm{H}$ NMR $\left(400 \mathrm{MHz}, \mathrm{CDCl}_{3}\right): \delta=9.78(\mathrm{~s}, 1 \mathrm{H}), 7.57-7.62(\mathrm{~m}, 7 \mathrm{H}), 7.37-7.39(\mathrm{~m}$, 3H), 7.23-7.29 (m, 7H), 7.08-7.17 (m, 5H), 6.82-6.94 (m, 4H), $3.88(\mathrm{t}, 2 \mathrm{H}), 1.80(\mathrm{~m}$, $2 \mathrm{H}), 1.41(\mathrm{~s}, 12 \mathrm{H}), 1.26-1.32(\mathrm{~m}, 6 \mathrm{H}), 0.86(\mathrm{~m}, 3 \mathrm{H})$. Anal. Calcd $(\%)$ for $\mathrm{C}_{57} \mathrm{H}_{52} \mathrm{~N}_{2} \mathrm{OS}$ : C, 84.20; H, 6.45; N, 3.45. Found: C 84.01, H 6.21, N 3.56.

\section{3-(7-[4-\{N,N-bis(9,9-dimethylfluoren-2-yl)amino\}styryl]-10-hexyl-10H-}

phenothiazin-3-yl)-2-cyanoacrylic acid (2). Compound 2 was synthesized by the similar method described for 1. 2(201 mg, 61.8\% yield, red solid. M.p. $112{ }^{\circ} \mathrm{C} .{ }^{1} \mathrm{H}$ NMR (400 MHz, DMSO-d $\left.{ }_{6}\right): \delta=7.86(\mathrm{~s}, 1 \mathrm{H}), 7.68-7.76(\mathrm{~m}, 5 \mathrm{H}), 7.37-7.50(\mathrm{~m}, 6 \mathrm{H})$, 7.23-7.33 (m, 7H), 6.99-7.10 (m, 8H), $3.90(\mathrm{t}, 2 \mathrm{H}), 1.68(\mathrm{~m}, 2 \mathrm{H}), 1.35(\mathrm{~s}, 12 \mathrm{H}), 1.25$ $(\mathrm{m}, 6 \mathrm{H}), 0.82(\mathrm{t}, 3 \mathrm{H})$. Anal. Calcd (\%) for $\mathrm{C}_{60} \mathrm{H}_{53} \mathrm{~N}_{3} \mathrm{O}_{2} \mathrm{~S}: \mathrm{C}, 81.88 ; \mathrm{H}, 6.07 ; \mathrm{N}, 4.77$. Found: C 81.11, H 5.87, N 4.52.

7-(7-[4-\{N, N-bis(9,9-dimethylfluoren-2-yl)amino\}styryl]-10-hexyl-10Hphenothiazin-3-yl)vinyl)-10-hexyl-10H-phenothiazine-3-carboxaldehyde

Compound 10 was synthesized by the similar method described for $\mathbf{8} .10$ (192 mg, 
55.3\% yield, yellowish solid). M.p. $93{ }^{\circ} \mathrm{C} .{ }^{1} \mathrm{H}$ NMR (400 MHz, $\mathrm{CDCl}_{3}$ ): $\delta=9.69$ (s, 1H), 7.47-7.55 (m, 6H), 7.01-7.31 (m, 16H), 6.70-6.89 (m, 12H), 3.83-3.89 (m, 4H), 1.76-1.85(m, 4H), $1.34(\mathrm{~s}, 12 \mathrm{H}), 1.17-1.24(\mathrm{~m}, 12 \mathrm{H}), 0.77-0.81(\mathrm{~m}, 6 \mathrm{H})$. Anal. Calcd (\%) for $\mathrm{C}_{77} \mathrm{H}_{73} \mathrm{~N}_{3} \mathrm{OS}_{2}$ : C, 82.53; H, 6.57; N, 3.75. Found: C 82.24, H 6.42, N 3.35.

\section{3-(7-(7-[4-\{bis(9,9-dimethylfluoren-2-yl)amino\}styryl]-10-hexyl-10H-}

phenothiazin-3-yl)vinyl)-10-hexyl-10H-phenothiazin-3-yl)-2-cyanoacrylic acid

(3). Compound 3 was synthesized by the similar method described for 1. 3(43 mg, $25.5 \%$ yield, red solid). M.p. $121{ }^{\circ} \mathrm{C} .{ }^{1} \mathrm{H}$ NMR (400 MHz, DMSO-d 6 ): $\delta=7.89$ (s, $1 \mathrm{H})$, 7.55-7.77 (m, 5H), 7.28-7.34 (m, 8H), 6.91-7.20 (m, 16H), 6.73-6.81(m, 5H), 3.78-3.93 (m, 4H), 1.63-1.65(m, 4H), 1.17-1.34 (m, 24H), 0.70-0.90 (m, 6H). Anal. Calcd (\%) for $\mathrm{C}_{80} \mathrm{H}_{74} \mathrm{~N}_{4} \mathrm{O}_{2} \mathrm{~S}_{2}:$ C, 80.91; H, 6.28; N, 4.72. Found: C 80.74, H 6.04, N 4.56 .

\section{References}

1. M. J. Kim, Y. J. Yu, J. H. Kim, Y. S. Jung, K. Y. Kay, S. B. Ko, C. R. Lee, I. H. Jang, Y. U. Kwon, N. G. Park, Dyes and Pigments, 95, 2012, 134.

2. S. Kim, H. Choi, C. Baik, K. Song, S. O. Kang, J. Ko, Tetrahedron, 2007, 63, 11436.
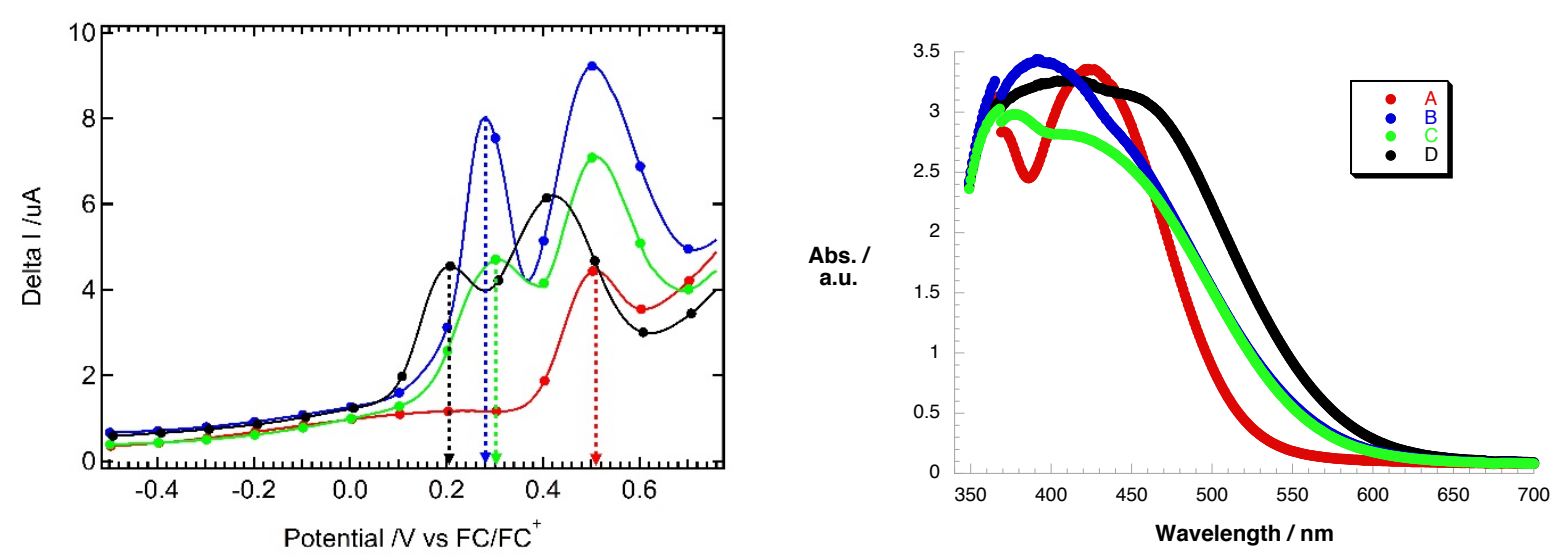

Figure S1. DPV measurements of the different dyes (left). Absorption spectra of the A, B, $\mathbf{C}$ and $\mathbf{D}$ as deposited on $3 \mu \mathrm{m} \mathrm{TiO}_{2}$ films (right). 

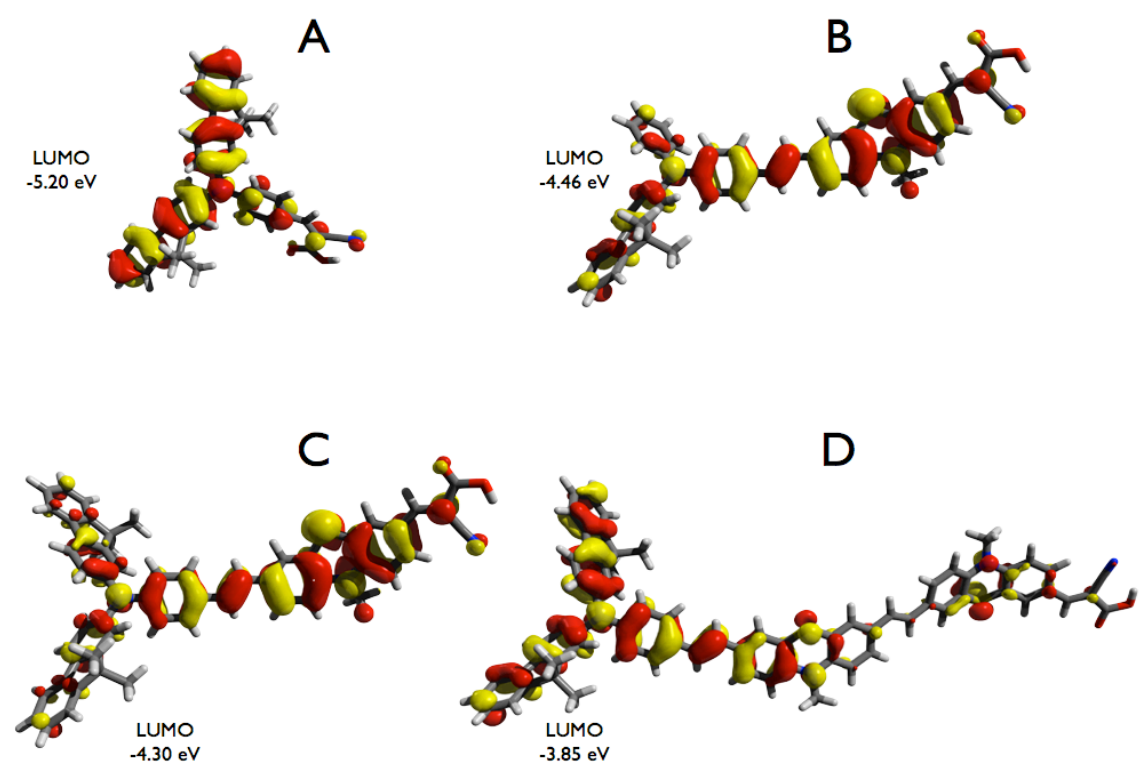

Figure S2. LUMO representations with the corresponding energies of the oxidized state of A, B, C and D as computed using the unrestricted B3LYP/6-31G* DFT method.

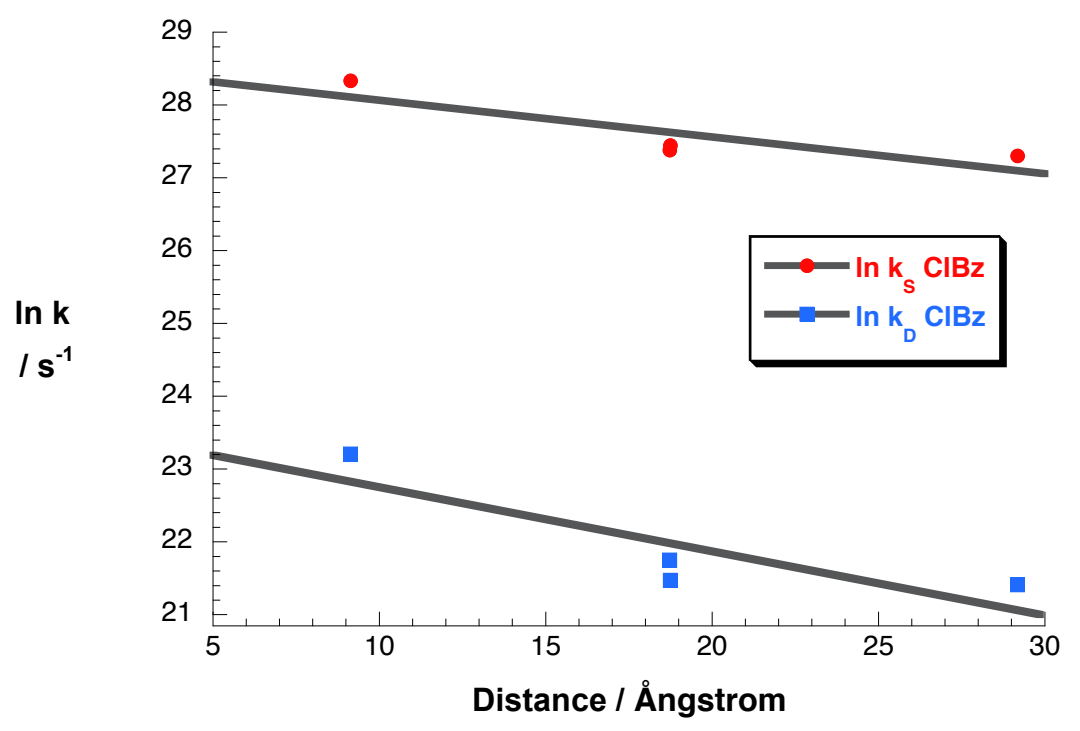

Figure S3. Representation of the dependence of the singlet excited state formation $\left(\ln k_{S}\right)$ and its deactivation $\left(\ln k_{D}\right)$ rate constants as of function of the donor-to-acceptor distances $\left(R_{D A}\right)$ for all dyes in nitrogen-saturated chlorobenzene. The slopes represent the different $\beta$ values for excitation (red) and deactivation (blue) of $\mathbf{A}, \mathbf{B}, \mathbf{C}$ and $\mathbf{D}$. 


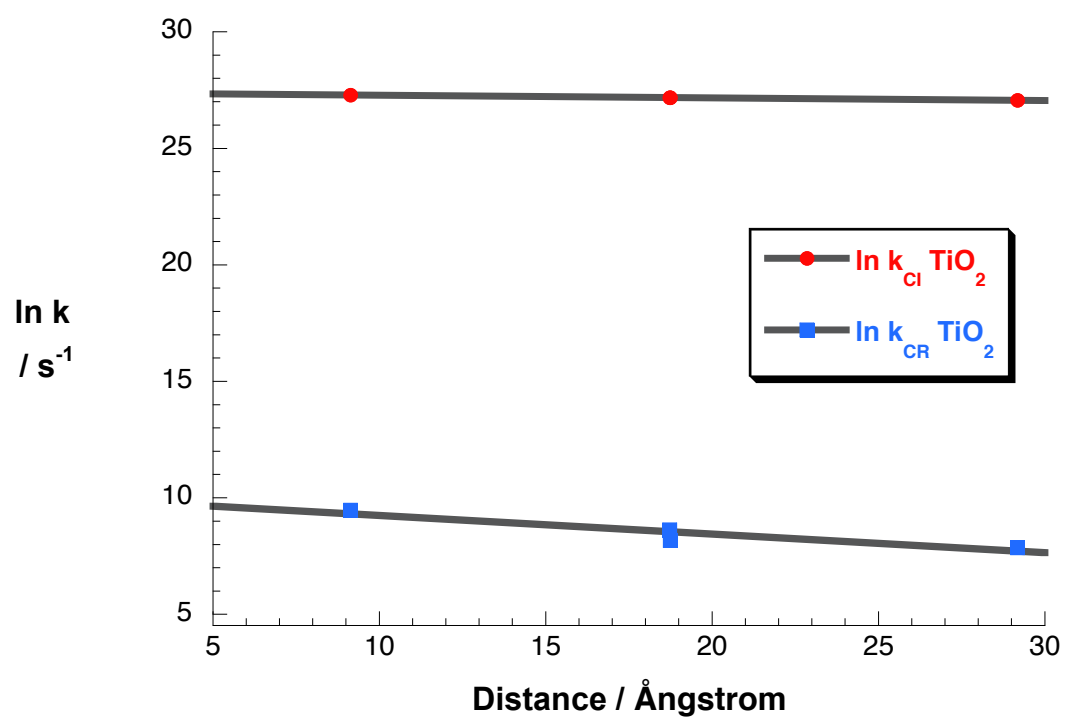

Figure S4. Representation of the dependence of the charge-injection $\left(\ln k_{C I}\right)$ and charge recombination $\left(\ln k_{C R}\right)$ rate constants on the donor-to-acceptor distances $\left(R_{D A}\right)$ for all dyes on $3 \mu \mathrm{m}$ thick $\mathrm{TiO}_{2}$ films. The slopes represent the different $\beta$ values for charge injection (red) and charge recombination (blue) of A, B, C and D. 


\section{Photovoltaic data, IPCE and Impedance results}
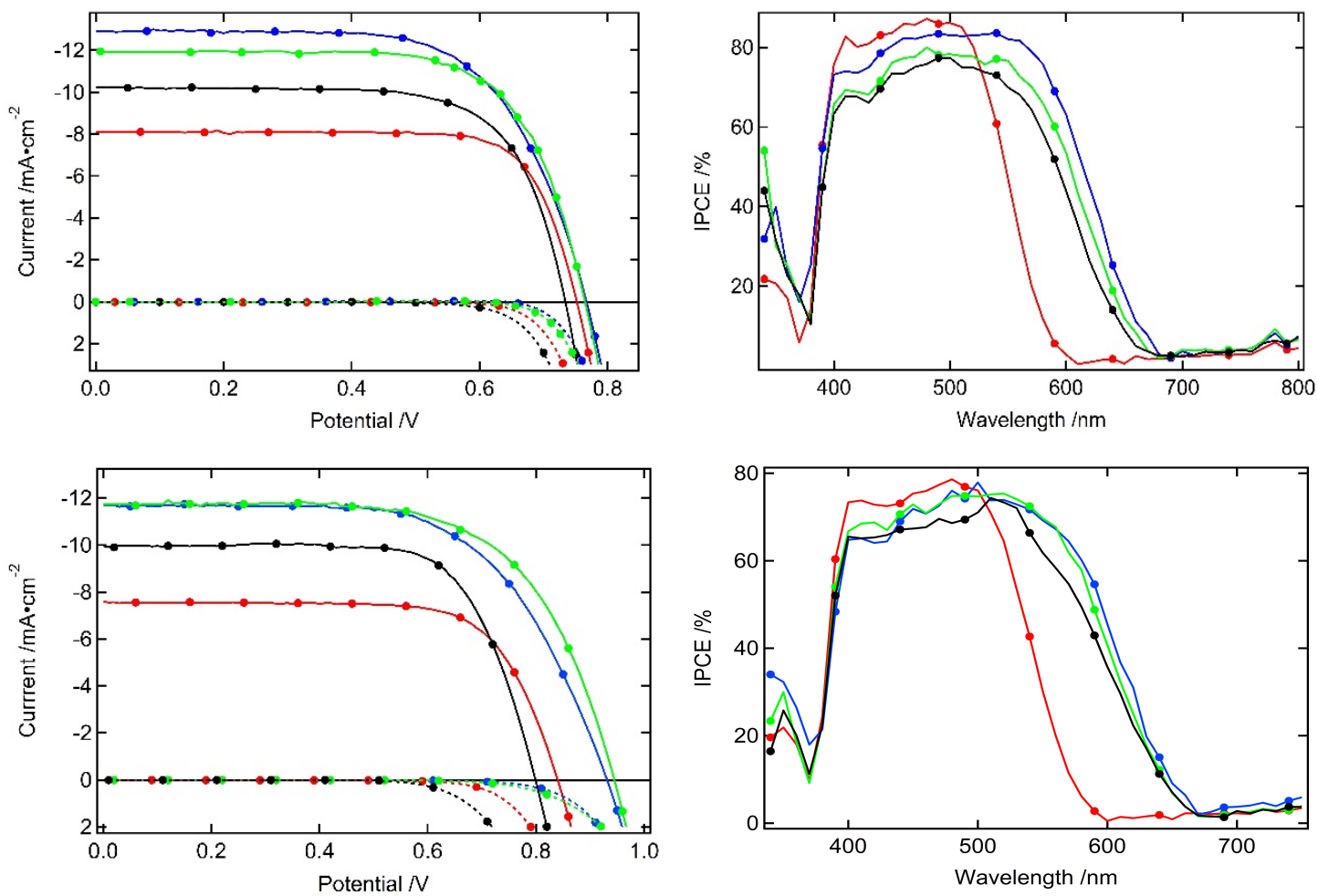

Figure S5 I-V curves showing PCE and dark current of devices made with Z952 (upper) and the corresponding IPCE and Z1147 (lower) electrolyte. Color code: A: red; B: blue; C: green, D: black. 

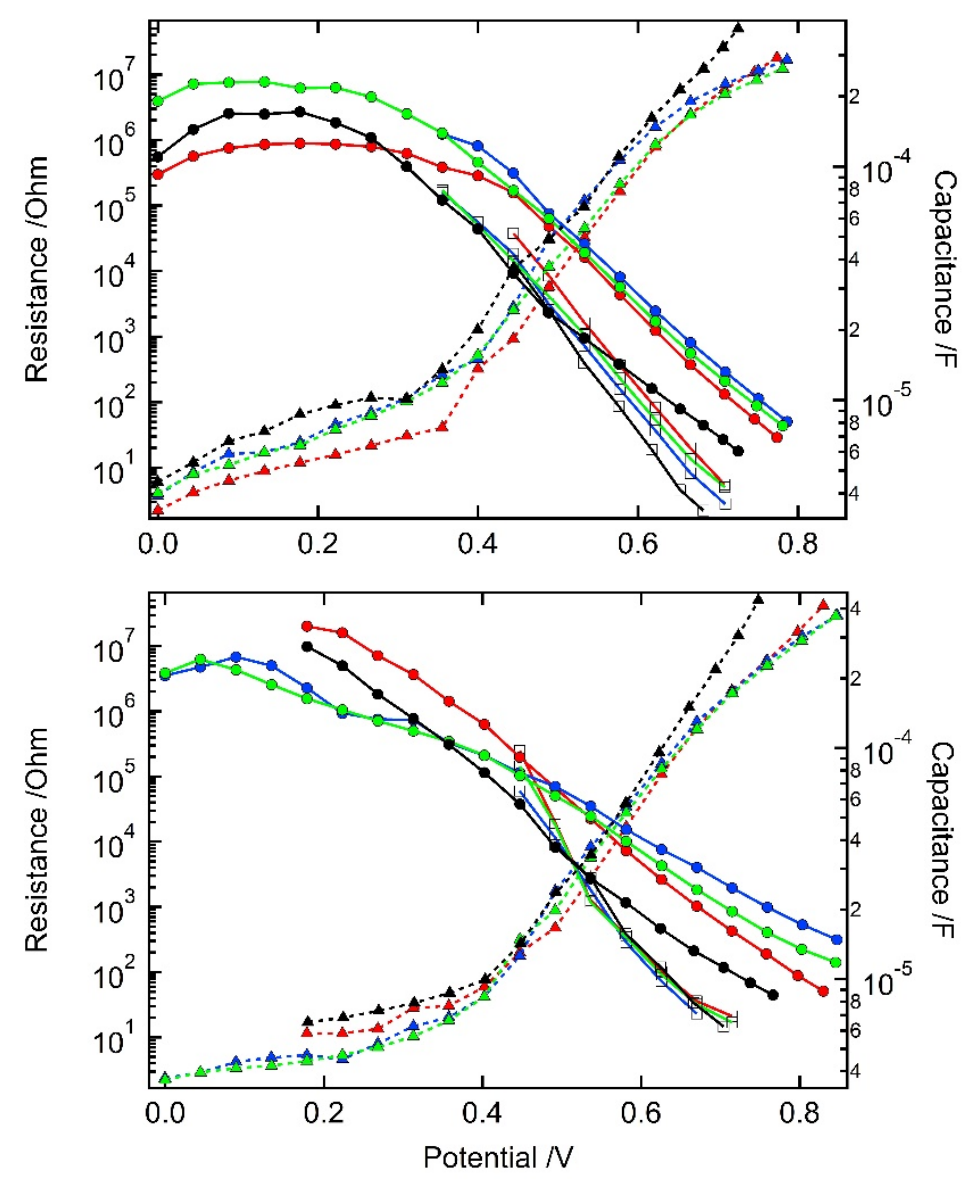

Figure S6 Representation of the recombination (filled circles) and transport (empty squares) resistance as well as the chemical capacitance of (dotted line) the $\mathrm{TiO}_{2}$ extracted from the EIS measurements for the Z952 and Z1147 electrolyte. Color code: A: red; B: blue; C: green, D: black. 

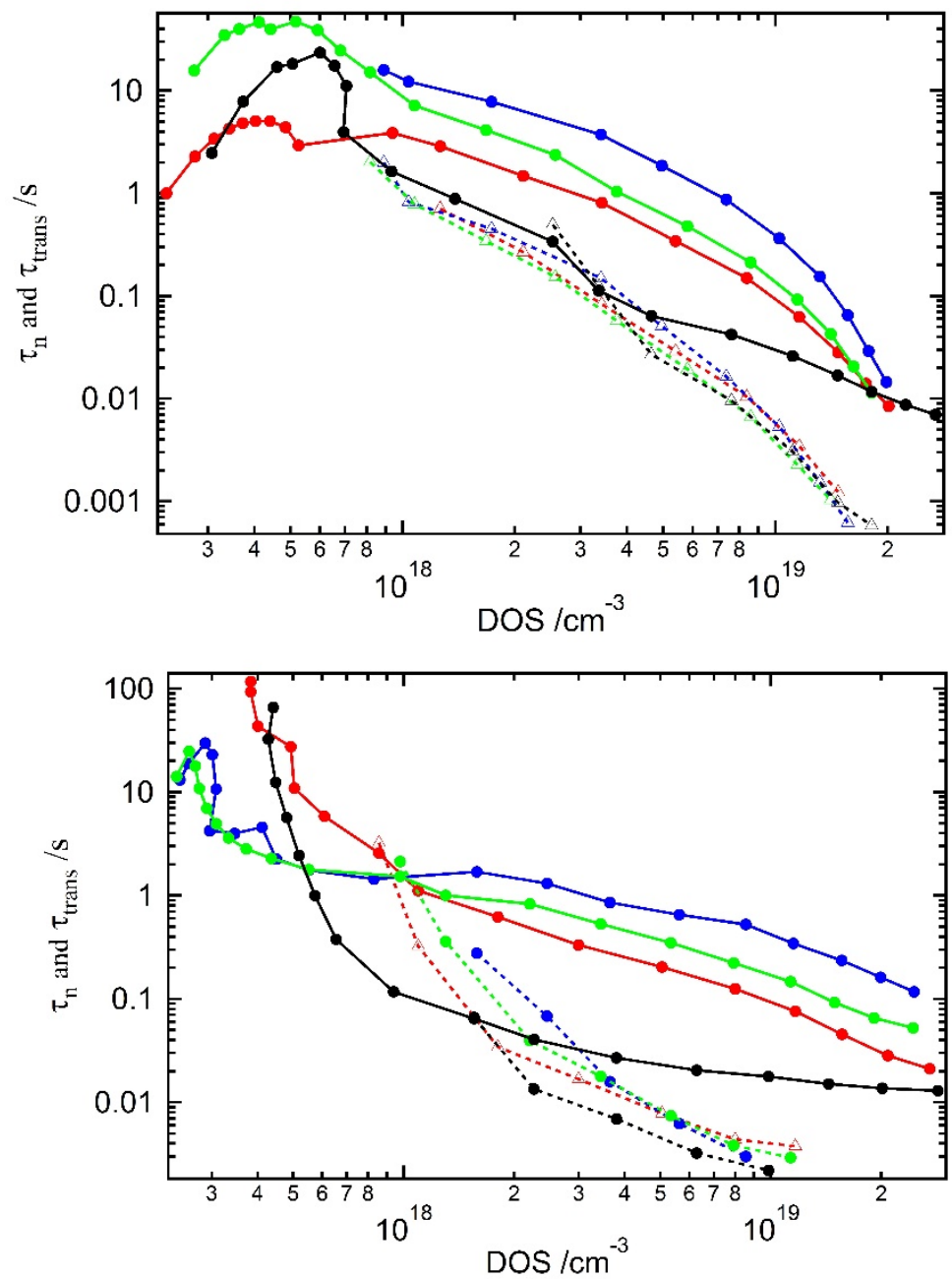

Figure S7 Representation of the electron lifetime (filled circles) and transport time (empty squares) extracted from the EIS measurements for the Z952 (upper) and Z1147 (lower) electrolyte. Color code: A: red; B: blue; C: green, D: black. 